\title{
Finite Element Modelling of Deformation Characteristics of Historical Stone Masonry Shear Walls
}

\author{
by \\ R. Senthivel* and P.B. Lourenço \\ Department of Civil Engineering, University of Minho, Guimarães, Portugal.
}

\begin{abstract}
Two dimensional nonlinear finite element analysis based on experimental test data has been carried out to model deformation characteristics, such as load-displacement envelope diagrams and failure modes of historical stone masonry shear walls subjected to combined axial compression and lateral shear loading. An experimental research work was carried out on three different types of historical stone masonry shear walls that can be considered representative of ancient stone masonry constructions. Those three types of masonry are: i) sawn dry-stack or dry-stone masonry without bonding mortar, ii) irregular stone masonry with bonding mortar, and iii) rubble masonry with irregular bonding mortar thickness. Plasticity theory based micro modelling techniques has been used to carry out the analysis. The stone units were modelled using an eight node continuum plane stress elements with full Gauss integration. The joints and unitjoint interfaces were modelled using a six node zero thickness line interface elements with Lobatto integration. This paper outlines the experimental research work, details of numerical modelling carried out and report the numerical lateral load-displacement diagrams and failure modes. The numerical analysis results were compared with the experimental test results and good agreement was found.
\end{abstract}

Keywords: Shear wall, FEM, Stone masonry, deformation characteristics, Failure modes, Interface elements.

\section{Introduction}

Stone masonry is the most ancient, durable, and widespread building method devised by mankind. Stone structures built without mortar rely on the skill of the craftsmen and the forces of gravity and frictional resistance. Stone has been a successful building medium

\footnotetext{
* Corresponding author; Tel.: +351 963614995; Fax: +351 253510217; E-mail: drsenthivel@yahoo.com
} 
throughout the ages and around the world because of its unique range of benefits. The structures are remarkably durable and, if correctly designed, can be made earthquake resistant. They resist fire, water, and insect damage. The mason needs a minimum of tools; the work is easily repaired; the material is readily available and is recyclable. Dry stone masonry, aesthetically, complements and enhances the landscape. Archaeologists have determined that the Chinese built dry stone terraces at least 10,000 years ago. In Britain, ancient tribes built dry stone shelters just after the last ice age, 8,000 years ago. High quality stone tools recently found in Europe are 2.2 million years old. The technique of dry stacking in construction has existed in Africa for thousands of years. The Egyptian pyramids and the Zimbabwe ruins, a capital of ancient Shona Kingdom around 400AD, are good examples. In addition to the neglect and destruction of historic structures, the craft is handicapped due to lack of technical information and skilled preservation personnel. Construction and engineering data that professionals need are scarce and, if recorded at all, are difficult to locate.

A large part of historical buildings are built with: i) sawn dry-stack or dry-stone masonry without bonding mortar; ii) irregular stone masonry with bonding mortar; iii) rubble masonry with irregular bonding mortar thickness; iv) a combination of the three techniques. When bonding mortar is used, it is usually low strength. In addition, masonry with mortar joints can experience a significant loss of mortar due to combined chemical, physical and mechanical degrading. Due to the partial or total disappearance of mortar, the behaviour of these constructions can then become similar to those made of dry joint masonry.

The primary function of masonry elements is to sustain vertical gravity load. However, structural masonry elements are required to withstand combined shear, flexure and compressive stresses under earthquake or wind load combinations consisting of lateral as well as vertical loads. Only few experimental results are available on the behaviour of stone masonry walls, e.g. Chiostrini and Vignoli (1992) addressed strength properties and Tomaževič (1999) reported tests on strengthening and improvement of the seismic performance of stone masonry walls. More recently, Corradi et al. (2003) carried out an 
experimental study on the strength properties of double-leaf roughly cut stone walls by means of in-situ diagonal compression and shear-compression tests.

A comprehensive experimental and numerical study on historical dry stone masonry walls has been reported by Lourenço et al. (2005). Displacement controlled experimental study for masonry walls under combined compression and shear loading was done for monotonic loading. Based on the material properties obtained from the experimental tests, numerical analysis was carried out to model the monotonic loaddisplacement diagrams using non-linear finite elements. Similar numerical modelling using rigid blocks limit analysis and discrete element analysis has been carried out by Azevedo et al. (2000) and Orduña and Lourenço (2003). However, these studies were limited to regular (sawn) dry stack mortarless stone masonry only. A detailed literature survey on numerical modelling of monuments and historical constructions including structure and component level are presented by Lourenço (2002) and Lemos (2007).

A research program was carried out by Vasconcelos (2005) at University of Minho to experimentally evaluate the in-plane seismic performance of ancient stone masonry without and with bonding mortar of low tensile strength to simulate the existing ancient stone masonry structures. Monotonic and reversed cyclic loading tests with three different pre-compression loading (low, moderate and high) were performed to investigate the strength, deformation capacity, load-displacement hysteresis response, stiffness characterization and failure modes. The data obtained from this experimental research has been used as a base for the present numerical analysis. The objective of the analysis carried out here was limited to modelling the peak load points of reversed cyclic hysteresis diagrams, or the so-called load-displacement envelope diagram, and failure modes of three different types of ancient stone masonry subjected to three different axial pre-compression loads.

Masonry is highly anisotropic due to the presence of discrete sets of horizontal and vertical mortar joints. Lourenço (1996a), Saadeghvaziri and Mehta (1993), Papa (2001) have divided models for masonry into two categories: micro and macro. Figure 1 shows details of micro and macro modelling techniques. Figure $1 \mathrm{~b}$ shows a detailed micro- 
modelling where joints are represented by mortar continuum elements and discontinuum interface elements. Figure 1c shows simplified micro-modelling where joints are represented by discontinuum elements. Figure 1d shows macro-modelling where joints are smeared out in the continuum. In the micro-modelling techniques, it is possible to model the unit-mortar interface and mortar joint which is responsible for most cracking as well as slip. Young's modulus, Poisson's ratio, inelastic properties of both unit and mortar are taken into account in the micro-modelling. The interface represents a potential crack/slip plane with dummy stiffness to avoid interpenetration of the continuum. Due to the zero thickness of the interface elements, the geometry of the unit has to be expanded to include the thickness of the joint. In the macro-modelling technique, mortar is smeared out in the interface element and in the unit.

In micro models, masonry units and mortar are separately discretised using continuum or discrete elements, whereas in the macro model (also known as equivalent material model), masonry is modelled as a single material using average properties of masonry. Page (1978) made an attempt to use a micro-model for masonry structures assuming units as elastic continuum elements bonded with interface elements. Arya and Hegemier (1978) proposed a von Mises strain softening model for compression with a tension cutoff for the units. Joints were modelled using interface elements with softening on both the cohesion and friction angle. The collapse load obtained from their model shows good agreement with experimental results from shear walls testing. Ghosh et al. (1994) concluded that macro modelling could predict the deformations satisfactorily at low stress levels and inadequately at higher stress levels when extensive stress redistribution occurs. Pande et al. (1990) categorically stated that macro modelling would not accurately predict the stress distribution within the units and mortar. In micro modelling, two approaches are followed in finite element analyses. In the first, both the units and the mortar joints are discretised by using continuum finite elements, whereas in the second approach interface elements are used to model the behaviour of mortar joints. Several researchers (Papa (2001), Lourenço and Rots (1997), Shing and Cao (1997)) have reported that the interface elements used in heterogeneous models reproduce essentially the interaction between two adjoining masonry units, and further degrees of freedom are not required to be introduced. 
For masonry walls subjected to either vertical load only or a combined shear and vertical loading, 2-D analyses are found effectively producing stress results that are close to those produced by 3-D analyses. Dhanasekar and Xiao (2001) proposed a special 2D element and validated its results using a 3D model of masonry prisms. To determine the internal stress distribution in unreinforced masonry, Page (1978) modelled joints as linkage elements in conjunction with units as plane stress continuum elements. Dhanasekar et al. (1985) proposed a macro model for solid masonry, which was capable of reproducing the effects of material nonlinearity and progressive local failure. To determine the internal stress distribution in masonry panels under concentrated loading, Ali and Page (1988) modelled the masonry units and mortar joints separately. They used four-noded quadrilateral elements with refined mesh in concentrated load regions to allow redistribution of stresses. Khattab and Drysdale (1994) also formulated a homogeneous model of masonry with considerations of mortar joints as planes of weakness.

Lourenço and Rots (1997) modelled masonry units as continuum elements while mortar joints and potential cracks in units were represented as zero-thickness interface elements. Interface elements were modelled with a cap model to include all possible failure mechanisms of masonry structures. The following failure mechanisms (Figure 2) are considered; a) cracking in the joint (Figure 2a), b) sliding along bed or head joints at low values of normal stress (Figure 2b), c) Cracking of the units in direct tension (Figure 2c), d) diagonal tension cracking of the units at values of normal stress sufficient to develop friction in the joints (Figure 2d) and e) Splitting of the units in tension as a result of mortar dilatancy at high values of normal stress (Figure 2e). This model has been used successfully to reproduce the complete path of the loaddisplacement diagram for standard masonry and dry stacked sawn masonry. An extension for cyclic loading using bounding surface plasticity is given in Oliveira and Lourenço (2004). The novelty of the present paper is in the application of the micromodel to simulate the response of rubble masonry.

\section{Outline of Experimental Research Program}

The experimental research work was carried out by Vasconcelos (2005) in the Structural Engineering Laboratory at the University of Minho, Guimarães, Portugal. Test walls 
were made of locally available two mica and medium grain granite stone. A ready-mix mortar made of naturally hydrated lime and aggregates of granular size between 0.1 and $0.2 \mathrm{~mm}$ was used to bond the units. The seven days average compressive strength of mortar was $3 \mathrm{~N} / \mathrm{mm}^{2}$ which was considered to be close to the strength of mortar found in ancient building constructions.

The main object of the experimental research work was to evaluate the in-plane seismic performance of stone masonry shear walls found in ancient masonry structures. Table 1 and Figure 3 and shows the three different types of experimental masonry test walls with description and dimensions respectively; Type I) Sawn dry-stone or dry-stack mortarless stone masonry (Figure 3a). This wall type was to represent historical masonry constructions where there is no bonding material between stone units or where most part of the bonding material of low strength vanished due to physical and mechanical weathering effect. Type II) Irregular stone masonry with bonding mortar (Figure 3b) can be representative of large stone block construction, possibly in wealthier housing and monumental buildings, and Type III) Rubble masonry with irregular bonding mortar joint thickness (Figure 3c), can be representative of vernacular buildings and historical city centres houses. In case of type I masonry test specimen, all the units were mechanically sawn to achieve a smooth surface. Dimension of the sawn stone used in type I masonry was $200 \mathrm{~mm}$ (length) x $150 \mathrm{~mm}$ (height) x $200 \mathrm{~mm}$ (width). Type II masonry consisted of hand-cut irregular shaped units and low strength head and bed joint bonding mortar. The size of the irregular stone used in type II masonry was approximately 1.3 times larger than the sawn stone used in type I masonry. Type III masonry composed of mixed stones of different shape, size and texture and low strength mortar. The thickness of all three types of walls was $200 \mathrm{~mm}$ and single wythe. Considering the capacity of testing equipments available in the laboratory, the dimension of model masonry test walls was fixed as $1000 \mathrm{~mm}$ (length) x1200 mm (height) x $200 \mathrm{~mm}$ (width) and the height to length ratio was 1.2.

Figure $4 \mathrm{a}$ and $4 \mathrm{~b}$ shows the experimental test set-up and loading history respectively. Monotonic and reversed lateral cyclic tests were carried out with three distinct axial precompression load levels including low, $100 \mathrm{kN}\left(\sigma_{0}=0.5 \mathrm{~N} / \mathrm{mm}^{2}\right)$, moderate, $175 \mathrm{kN}$ 
$\left(\sigma_{0}=0.875 \mathrm{~N} / \mathrm{mm}^{2}\right)$ and high, $250 \mathrm{kN}\left(\sigma_{0}=1.25 \mathrm{~N} / \mathrm{mm}^{2}\right.$. The base of the walls was fixed to the test floor and the first course of the wall was horizontally supported using a special arrangement consists of steel plates, angles, bolt, and nuts. To test the experimental test set-up, a monotonic load test on Type I masonry was made. The preliminary test was carried out by increasing the load steadily until failure of the wall. From the preliminary test results, a load-displacement curve was established for Type I. After the successful completion of the monotonic test, the reversed lateral cyclic load tests were carried out of all three types of masonry according to pre-defined load history presented in Figure $4 b$.

Construction of all three types of test walls was performed manually by the same mason to ensure uniform workmanship. For easy transportation and to avoid local damage during transit, test walls were built on thick steel beam. Construction of type I masonry wall was easier and straight forward. Horizontal and vertical alignments of the wall were checked using plumb during the construction of each course. As there is no curing involved, the wall was ready to test immediately after the construction. Type II and III masonry test walls were constructed using low strength bonding mortar, cured for 7 days under damped condition and tested. Before construction, the units were soaked in water to avoid absorption of water from the mortar during construction and shrinkage during curing. A total number of twenty four walls have been tested including ten type I walls, seven type II walls and seven type III walls. Table 2 shows the total number of walls tested in each masonry type and under different axial pre-compression loading.

Axial pre-compression loading was applied by using a vertical actuator with a maximum capacity of $250 \mathrm{kN}$. Through a set of roller supports, a deep and stiff beam was used to distribute vertical load from the actuator to a thick steel beam (similar to the base beam) that was erected on top the wall after construction. The axial precompression load (either 100 or 175 or $250 \mathrm{kN}$ ) was kept constant throughout the test using an independent dedicated oil pressure system. The top thick stiff steel beam was also used to apply the shear lateral load from the horizontal actuator as shown in Figure 4a. The purpose of the steel rollers placed between the deep beam and top beam, was to allow the wall to displace horizontally during the application of lateral shear load. Care 
was taken to avoid possible out-of-plane movement of test wall during the lateral load application. After applying the desired axial pre-compression load, the lateral load was applied in terms of controlled displacement at the rate of $100 \mu \mathrm{m} / \mathrm{s}$. Deformation of the walls was measured using needle type Linearly Variable Differential Transducers (LVDTs) mounted on different critical regions, Figure 4a, and on both sides of the wall. The monotonic load test was done for type I masonry only. Reversed cyclic shear loading test was carried out for all the masonry types.

Here, it is noted that the experimental envelop curves on reversed cyclic test will be assumed as representative of quasi static monotonic loading. It is certain that the envelopes for the former do not exactly coincide with the later. The authors are not aware of specific papers addressing this issue but no significant differences are expected in terms of peak load, as energy dissipation in the hysteretic behaviour of shear walls seems to be mostly related to compressive failure and large drifts. In Oliveira and Lourenço (2004), for a severely compressed and asymmetric wall, a difference of about $10 \%$ was found in terms of peak load, while comparing monotonic response versus cyclic envelop. For the masonry type I above (regular / sawn dry stone masonry) of the present experimental campaign, similar results were found for monotonic and reversed cyclic loading tests, Vasconcelos (2005).

\section{Finite Element Analysis of Stone Masonry}

The data obtained from the ancient stone masonry shear wall test carried out by Vasconcelos (2005) has been used as a base for the present finite element modelling. Prior to the testing of model masonry walls, mechanical tests such as compression, tension and shear tests were done on stone unit, mortar cubes, prisms made out of mortarless dry-stone, irregular stone with boding mortar and rubble stone with bonding mortar. These tests on materials were done to determine the elastic, inelastic and strength parameters required for the present finite element modelling. Average compressive strength, tensile strength and Young's modules of stone was $69.2 \mathrm{~N} / \mathrm{mm}^{2}$, $2.8 \mathrm{~N} / \mathrm{mm}^{2}$ and $20200 \mathrm{~N} / \mathrm{mm}^{2}$ respectively. Average compressive strength of mortar was $3.0 \mathrm{~N} / \mathrm{mm}^{2}$. 


\subsection{Mesh Generation and Element Selection}

For type 1 (dry-stack stone masonry), the finite element mesh was generated using a FORTRAN program developed by Lourenço (1996b). The following input data was required to generate a mesh for regular masonry walls such as type I; i) whether potential vertical cracks in the middle of the units are to be included in the model, ii) whether a masonry joint is to be included in the bottom of the model, iii) whether a masonry joint is to be included in the top of the model, iv) whether each course contains an integer number of units, v) whether the first (bottom) course starts with a full unit or half unit, vi) the number of masonry courses in the model, vii) the number of complete units per course, viii) the number of divisions (finite elements) per unit in the $\mathrm{x}$ direction, ix) the number of divisions (finite elements) per unit in the $y$ direction, $x$ ) the width of the units (plus $1 / 2$ of thickness of the mortar joint), xi) the height of the units (plus $1 / 2$ of thickness of the mortar joint), xii) the half of a thin fake joint thickness for joints, only for visual or identification purposes. Figure 5a shows division of units in $\mathrm{x}$ and y directions, interface around the unit and fake thickness of joints. Figure $5 b$ shows a possible potential crack at the middle of the stone unit.

As the experimental test results showed no cracks in the unit, potential cracks in the units were not considered in the entire modelling work for all three types of masonry. The FORTRAN programme cannot be used for type II or III as it has complex irregular units of different texture and size. For type II and III masonry, the nodal points were calculated using a special image scanning software and Microsoft Excel, and the rest of the meshing procedure is same as that of the Type I masonry.

The units were modelled using eight node quadrilateral isoparametric continuum plane stress elements, CQ16M (Figure 6a), with quadratic interpolation and full Gauss integration. The joints were modelled using a six node and zero thickness line interface elements, CL12I (Figure 6b) with Lobatto integration. Figure 6c shows the unit and interface element assemblage. 


\subsection{Material Properties (Strength, Elastic and Inelastic Parameters)}

The average Young's modulus of dry-stone prisms was $14800 \mathrm{~N} / \mathrm{mm}^{2}$ (based on test results of four prisms built with four course dry-stacked stones). Young's modulus of large walls is usually different from the Young's modulus measured in small test specimens. This phenomenon has been found and reported by Lourenço (1996a). Micromodelling approach based on interface finite elements requires two distinct stiffnesses, namely, the stiffness of the stone units and the stiffness of the joints. Once the stiffness of the stone units is known, the stiffness of the joints can be calculated from the experimental axial pre-compression load-displacement curve of the walls. Normal joint stiffness $\left(\mathrm{K}_{\mathrm{n}}\right.$, joint $)$ was calculated using the following formulation proposed by Lourenço (1996a) in which the wall is consider as a series of two springs in vertical direction, one representing the stone and the other representing the joint.

$$
\mathrm{K}_{\mathrm{n}, \mathrm{joint}}=1 /\left(\mathrm{h}\left(1 / \mathrm{E}_{\mathrm{wal}}-1 / \mathrm{E}_{\text {stone }}\right)\right)
$$

where

$$
\begin{array}{ll}
\mathrm{K}_{\mathrm{n}, \text { joint }} & =\text { Normal joint stiffness } \\
\mathrm{h} & =\text { Height of stone }(150 \mathrm{~mm}) \\
\mathrm{E}_{\text {wall }} & =\text { Young's modulus of wall } \\
\mathrm{E}_{\text {stone }} & =\text { Young's modulus of stone }
\end{array}
$$

The tangential stiffness $\left(\mathrm{K}_{\mathrm{s} \text {, joint }}\right)$ was calculated directly from the normal stiffness using the theory of elasticity as follows, Lourenço (1996a):

$$
\mathrm{K}_{\mathrm{s}, \text { joint }}=\mathrm{K}_{\mathrm{n}, \text { joint }} / 2(1+\mathrm{v})
$$

where

$$
\begin{array}{ll}
\mathrm{K}_{\mathrm{s}, \text { joint }} & =\text { Normal joint stiffness } \\
\mathrm{v} & =\text { Poisson's ratio }(0.2)
\end{array}
$$

The following inelastic properties of unit-mortar interface were taken in to account (Lourenço \& Rots [1997]): i) tensile criterion: $f_{t}$ (tensile strength) and $G_{f}{ }_{f}$ (fracture 
energy for Mode-I); ii) friction criterion: $c$ (cohesion), $\tan \varphi$ (tangent of the friction angle), $\tan \psi$ (tangent of the dilatancy angle) and Mode-II fracture energy, $G_{\mathrm{f}}{ }_{\mathrm{fI}}$; iii) cap criterion: $f_{c}$ (compressive strength) and $\mathrm{G}_{\mathrm{f}}^{\mathbf{c}}$ (compressive fracture energy). The inelastic parameters required for the analysis were extracted from Vasconcelos (2005), when available, or followed the recommendations given in Lourenço (1996a). Table 3 and 4 presents elastic and inelastic parameters. Again, note that the elastic stiffness of the interfaces was adjusted from the measured experimental results, becoming clear that the stiffness decreases consistently from Type I to Type III, due to the increasing thickness of the joint and irregular shape of the units. The equations that govern the inelastic behaviour of masonry are given in detail in Lourenço and Rots (1997), where it is assumed exponential softening for tension and for shear, followed by parabolic hardening, parabolic softening and exponential softening in compression, see Figure 7.

\subsection{FEM Analysis Procedure}

Firstly (step-1), the desired total vertical pre-compression load (either $100 \mathrm{kN}$ or $175 \mathrm{kN}$ or $250 \mathrm{kN}$ ) was dived in to small steps and gradually applied on the top surface of stiff steel beam (Figure 8). Then the horizontal load in terms of incremental displacement was applied in small steps at the top right corner of the steel beam (step-2). For a good insight into the stress distribution at different horizontal load increment, the horizontal displacement was increased gradually to $2.5 \mathrm{~mm}$, then to $5 \mathrm{~mm}$, then to $10 \mathrm{~mm}$ and lastly until the failure/ collapse, which provided the behaviour of each critical region (Figure 8 ) of the walls, in addition to the overall deformation characteristics. The vertical and horizontal loads were applied in small steps to achieve a converged solution, particularly in the case of dry stone masonry, which features no tensile strength or cohesion.

\subsection{FEM Analysis Results}

Results of the nonlinear finite element analysis were post processed and are presented in this section. Axial pre-compression load, lateral shear load and material properties are the main parameters that significantly influenced the behaviour of the shear walls. Load flow in the whole body of the wall at different lateral displacement levels, failure modes 
and state of load and displacement in critical nodes are presented in the following sections.

\subsubsection{Modes of Failure}

Heel, toe, centre and local point of application of load on the shear wall are the critical regions (Figure 8). Failure in these regions mainly controlled the overall behaviour of the shear walls. Walls failed due to either flexure or racking or toe crushing or tensile cracking at the heel followed by shear failure along the diagonal. Combination of two or more failures has also occurred at critical load level. At lower pre-compression levels $(100 \mathrm{kN})$, walls usually failed due to a progressive flexural mechanism characterised by heel cracking followed by rocking and toe crushing. Irrespective of masonry types, axial pre-compression stress significantly influenced the behaviour of the shear walls. A small increase in vertical load provided the walls with a larger strength due to the improvement of bond resistance mechanisms between joint and masonry units. A substantial increase of axial stress changes the failure mode of the wall from flexure to shear.

Figures 9, 10 and 11 present the deformed shape and the minimum principal (compressive) stresses of Type I, II and III masonry models respectively under different lateral displacement, and axial pre-compression loadings. Lower axial pre-compression load caused flexural or rocking failures and higher pre-compression load caused rocking, toe crushing, crushing at region of load application and diagonal shear failures along the diagonal direction. Flexural cracking in the bed joints occurs when the tensile stress on a horizontal mortar joint exceeds the sum of the bond strength of that mortar joint and the frictional stress between the mortar and the units. Rocking mode of failure occurs due to overturning caused by either low level of axial load and/or weak tensile bond strength of mortar joints dominated. Diagonal shear failure occurs when the diagonal tensile stress resulting from the compression shear state exceeds the splitting tensile strength of masonry.

Figure 9 details the progress of cracking and redistribution of compressive stresses upon loading, which leads to a series of struts defined by the geometry and stone 
arrangement. For a good insight into the stress distribution at different horizontal load increment, the horizontal displacement was increased gradually to $2.5 \mathrm{~mm}$, then to 5 $\mathrm{mm}$, then to10 $\mathrm{mm}$ and until the failure/ collapse, which provided the behaviour of the critical regions at different magnitude of applied loads. When the applied displacement is $2.5 \mathrm{~mm}$, a larger number of diagonal compressive struts are clearly formed and the whole wall is still mostly structurally sound. As the displacement increased from 2.5 $\mathrm{mm}$ to $5 \mathrm{~mm}$ and then to $10 \mathrm{~mm}$ etc, the number of compression struts reduced and diagonal cracking started to occur. A complete diagonal crack propagates and the failure mode is mostly controlled by shear, together with localized rocking of the cracked stone pieces in the compressed toe region of the wall. This agrees reasonably well with the failure mechanisms observed in experimental tests, see Figure 9.

The failure of Type II, irregular masonry is not so different from Type I, sawn masonry, even if the orientation of the diagonal crack is different and more shear failure is apparent, see Figure 10.

The deformed shape of original mesh of Type III, rubble masonry is shown in Figure 11a. Unexpectedly, the model failed in sliding along a weak plane at about mid-height, at very low level applied lateral load. This clearly indicates that failure is influenced by the irregular internal arrangement and unrealistic results can be obtained. To avoid the sliding failure, a shear key along the weak plane was provided by adding an extra corner to a four corner stone unit at middle of the weak plane/ path, and the original mesh was modified. The modified mesh was subsequently used in all analyses. Moreover, as the internal structure is not symmetric, the results are provided from Left to Right loading (L-R) and Right to Left loading (R-L). The deformed shapes at collapse for the modified mesh are shown in Figure 11b. Under different pre-compression levels, the failure occurred in the modified Type III mesh is not so different from the Type I and II masonry particularly at higher level of axial pre-compression load, including a diagonal shear crack and toe crushing. Certainly that a major difference is that not really stepped cracks are found, being the crack mostly straight. 


\subsubsection{Load-Displacement Curves}

From the experimental cyclic hysteresis curves, the peak load points were used to establish experimental load-displacement envelope curves. These experimental curves are compared with numerical results, and presented in Figure 12a-c, 13 and 14 for Type I, II and III masonry respectively. As mentioned in section 2, monotonic tests were performed for Type I (regular/ sawn) masonry only. The load-displacement envelope curve obtained under monotonic loading was superimposed with the envelope curves of cyclic loading and presented in Figure 12 d-f. As can be seen from the Figure 12d-f, these two (monotonic and cyclic) curves follow exactly a same path until the appearance of first crack at about $60-80 \%$ of failure load. After the appearance of crack in ascending zone, these two curves still follow the same path with little difference that can be neglected. After reaching close to failure, these two curves stabilize and follow exactly the same path again with increasing displacement and almost constant load level. Similar finding has been reported by Senthivel and Sinha (2002) for masonry subjected to monotonic and cyclic loading. For the rest of the case (Type II and III), it was assumed that the peak points of cyclic hysteresis curves approximately coincides the monotonic envelope curve.

Envelope curves of Type I masonry exhibited three different rages and trends: an initial linear portion with a high rate stiffness (which is directly proportional to the applied axial pre-compression load) followed by a transitory non-linear portion and, finally a relatively approximate linear portion with slow rate of increase in load and faster rate of increase in displacement. The similar trends can be seen in the case of type II and III masonry except for the sudden load drops occurred in the ascending branch of the curves due to movements or sliding of stones. Initially, the curves exhibited large stiffness with linear behaviour up to about $30 \%$ of the respective peak load. As the lateral load increases, stiffness degradation takes place. A good correspondence between numerical and experimental load-displacement curves has been found for Type I and Type II masonry.

In case of Type III, due to irregular and random assembly of units with different size and texture, the load-displacement response was sensitive to the direction of lateral load. 
This leads to a significant scatter of the results and less good agreement in the results, particularly for the case of higher precompression. Still, the asymmetry of the results can be replicated by the numerical results, see Figure 14. Possibly, better agreement could be obtained by fine tuning the adopted shape of the units for each test, but this is outside the scope of this paper.

Finally, it is noted that the model of Lourenço and Rots (1997) is not capable of reproducing adequately the crack closure and cannot be used for reversed cyclic loading. The cyclic loading model available, Oliveira and Lourenço (2004), requires significant additional data and experiences severe convergence difficulties upon a large number of cycles or large displacements, being the monotonic model much more robust. The combination of dry stacked masonry, which requires very small steps due to lack of tensile strength and cohesion, with cyclic loading makes the analysis process unwieldy. Therefore, no attempt is made here to replicate the cyclic results of the experimental testing program. It seems that more robust material models are needed for this purpose.

\section{Discussion and Conclusions}

Masonry is a material which exhibits distinct directional properties due to the mortar joints which act as planes of weakness. Large number of influence factors, such as anisotropy of units, dimension of units, joint width, material properties of the units and mortar, arrangement of bed as well as head joints and quality of workmanship, make the simulation of masonry difficult. The main objective of the present finite element modelling work was to evaluate analytically the in-plane seismic performance of three different types of stone masonry shear walls found in ancient masonry structures in Europe particularly in north of Portugal: Type I) Sawn dry-stone or dry-stack mortarless stone masonry, Type II) Irregular stone masonry with bonding mortar, and Type III) Rubble masonry with irregular bonding mortar joint thickness.

A plasticity theory based micro modelling techniques has been employed to carry out the analysis. The analysis results showed that the failure patterns and load-deformation response of the shear walls are highly influenced by the by axial pre-compression and material properties. The strength of masonry is different for type I, II and III but the 
behaviour remain almost same particularly under higher axial pre-compression $(175 \mathrm{kN}$ and $250 \mathrm{kN}$ ). Lower axial pre-compression load caused flexural or rocking failures and higher pre-compression load caused rocking, toe crushing and diagonal shear failures along the diagonal direction. The predicted numerical failure modes are in good correspondence with the experimental failure modes. The numerical and experimental load-displacement diagrams are compared and presented. A good correspondence between numerical and experimental response has been found for all the cases of precompression level.

\section{Acknowledgement}

The Authors would like to acknowledge Dr. D.V. Oliveira and Dr. G. Vasconcelos, Assistant Professors in the Civil Engineering Department at the University of Minho for their assistance during the present modelling work. The first author, R. Senthivel would like to acknowledge the Portuguese National Science and Technology Foundation (FCT), Lisbon for their financial support (Ref. No.: SFRH/ BPD/ 20924/ 2004) to carry out his Post-Doctoral Research in the Civil Engineering Department at the University of Minho, Portugal.

\section{REFERENCES}

1. Ali, S. and Page, A. W., "Finite element model for masonry subjected to concentrated loads." Journal of Structural Engineering, ASCE Vol.114 (8), 1988, pp.1761-1783.

2. Arya, S.K., Hegemier, G.A., "On non-linear response predictions of concrete masonry assemblies”, Proc. North American Masonry Conf., 1978, pp. 19.1-19.24.

3. Azevedo J, Sincrain G, Lemos J.V., "Seismic behaviour of blocky masonry structures”, Earthquake Spectra, 16 (2), 2000, pp. 337-365.

4. Chiostrini S, Vignoli A, "An experimental research program on the behaviour of stone masonry structures", Journal of Testing and Evaluation, Issue 3, Volume 20, 1992.

5. Corradi, M., Borri, A and Vignoli, A., "Experimental study on the determination of strength of masonry walls", Journal of Construction and Building Materials, Volume 17, Issue 5, July 2003, pp. 325-337.

6. Dhanasekar, M., Kleeman, P. W. and Page, A. W., "Biaxial stress -strain relations for brick masonry." Journal of Structural Engineering, ASCE, Vol.111 (5), 1985, pp.1085-1100. 
7. Dhanasekar, M. and Xiao, Q. Z., "Plane hybrid stress element method for 3D hollow bodies of uniform thickness." Computers and Structures Vol.79, 2001, pp.483-497.

8. Ghosh, A. K., Amde, A. M. and Colville, J., "Finite element modelling of unreinforced masonry", $10^{\text {th }}$ International Brick/Block Masonry Conference, Calgary, Canada, July 5-7, 1994, pp.61-69.

9. Khattab, M. M. and Drysdale, R. G., "Nonlinear modelling of the shear response of grouted and reinforced concrete masonry". 10th International Brick/Block Masonry Conference, Calgary, Canada, 1994, pp.1047-1056.

10. Lourenço, P.B., "Computational strategies for masonry structures, Ph.D. Dissertation, Delft University of Technology, Delft, The Netherlands, 1996a.

11. Lourenço, P.B., "A user/programmer's guide for the micro-modelling of masonry structures”, Relatório no 03.21.1.31.35, Universidade Técnica de Delft, Delft, Países Baixos e Universidade do Minho, Guimarães, Portugal, 1996b.

12. Lourenço, P. B., and J.G. Rots, "A multi-surface interface model for the analysis of masonry structures”, J. Struct. Eng., ASCE, 123, (7), 1997, pp. 660-668.

13. Lourenço, P.B., "Computations of historical masonry constructions", Progress in Structural Engineering and Materials, 4(3), 2002, pp. 301-319.

14. Lourenço, P.B., Oliveira, D.V., Roca, P., and Orduña, A, "Dry joint stone masonry walls subjected to in-plane combined loading", J. of Strcural Engineering, ASCE, Vo. 131, No. 11, 2005.

15. Lemos, J.V., "Discrete element modelling of masonry structures", International Journal of Architectural Heritage, Vol. 1(2), 2007, pp. 190-213.

16. Oliveira, D.V. and Lourenço, P.B., "Implementation and validation of a constitutive model for the cyclic behaviour of interface elements", Computers \& Structures, 82 (17-19), 2004, pp. 1451-1461.

17. Orduña, A., Lourenço, P.B., "Cap model for limit analysis and strengthening of masonry structures”, J. Struct. Engrg., ASCE, 129(10), 2003, pp. 1367-1375.

18. Page, A.W., "Finite element model for masonry", J. Struc. Engineering, ASCE, Vol. 104 (8), 1978, pp. 1267-1285.

19. Pande, G., N., Liang, J. X. and Middleton, J., "Equivalent elastic moduli for brick masonry" Computers and Geotechnics Vol.8, 1990, pp.243-265. 
20. Papa, E., "Damage and failure models. Computational modelling of masonry brickwork and blockwork structures", Saxe-Coburg publications, Stirling, Scotland, 2001, pp.1-26.

21. Saadeghvaziri, M. A. and Mehta, S., "An analytical model for URM Structures", $6^{\text {th }}$ North American Masonry conference, Philadelphia, Pennsylvania, 1993, pp.409418.

22. Senthivel, R. and Sinha, S.N., "Cyclic behaviour of brick masonry under uniaxial compression", Proceedings of the $6^{\text {th }}$ International Masonry Conference, British Masonry Society, UK, No.9, 2002.

23. Shing, P. B. and Cao, L. (1997). "Analysis of partially grouted masonry shear walls." U. S. Department of Commerce, National Institute of Standards and Technology, Gaitherburg, MD, NISTIR GCR 97-710, 1997.

24. Tomaževič, M. "Earthquake-resistant design of masonry buildings", Imperial College Press, London, 1999, ISBN: 1-86094-066-8.

25. Vasconcelos, G., "Experimental investigations on the mechanics of stone masonry: Characterization of granites and behaviour of ancient masonry shear walls", Ph.D. Dissertation submitted to University of Minho, Portugal, 2005, available at http://www.civil.uminho.pt/masonry/ 
Table 1: Type of experimental test walls

\begin{tabular}{|l|l|}
\hline \multicolumn{1}{|c|}{ Stone Masonry Wall Type } & \multicolumn{1}{c|}{ Description } \\
\hline Type I: Dry-stack sawn & $\begin{array}{l}\text { Sawn stone assembledge } \\
\text { without bonding mortar }\end{array}$ \\
Type II: Irregular & $\begin{array}{l}\text { Irregular stone assembledge } \\
\text { with bonding mortar }\end{array}$ \\
Type III: Rubble & $\begin{array}{l}\text { Rubble stone assembledge } \\
\text { with bonding mortar }\end{array}$ \\
\hline
\end{tabular}

Table 2: Details of stone masonry test specimen and axial pre-compression

\begin{tabular}{|c|c|c|c|c|}
\hline \multicolumn{2}{|c|}{ No. of Masonry Walls Tested } & \multirow{2}{*}{$\begin{array}{c}\text { Axial Pre-Compression } \\
\text { Level } \mathbf{( k N )}\end{array}$} & $\begin{array}{c}\text { Normal Stress } \\
\left(\mathbf{N} / \mathbf{m m}^{\mathbf{2}}\right)\end{array}$ \\
\cline { 1 - 3 } Type I & Type II & Type III & $100($ Low $)$ & 0.50 \\
3 & 2 & 2 & 175 (Moderate) & 0.875 \\
3 & 3 & 2 & 250 (High) & 1.25 \\
\hline
\end{tabular}

Table 3: Elastic Properties

\begin{tabular}{|c|c|c|c|}
\hline \multicolumn{2}{|c|}{ Unit } & \multicolumn{2}{c|}{ Joint (Stiffness) } \\
\hline $\begin{array}{c}\text { Young's Modulus, E } \\
\left(\mathrm{N} / \mathrm{mm}^{2}\right)\end{array}$ & $\begin{array}{c}\text { Poison's Ratio, } \\
\mu\end{array}$ & $\begin{array}{c}\text { Normal, } \mathrm{K}_{\mathrm{n}} \\
\left(\mathrm{N} / \mathrm{mm}^{2}\right)\end{array}$ & $\begin{array}{c}\text { Tangential, } \mathrm{K}_{\mathrm{s}} \\
\left(\mathrm{N} / \mathrm{mm}^{2}\right)\end{array}$ \\
\hline \multirow{2}{*}{20200} & \multirow{3}{*}{0.2} & $8.0($ Type I) & $3.33($ Type I) \\
\cline { 3 - 4 } & & $3.5($ Type II) & 1.575 (Type II) \\
\cline { 3 - 4 } & & $2.0($ Type III) & 0.9 (Type III) \\
\hline
\end{tabular}

Table 4: Inelastic Properties, Vasconcelos (2005)

\begin{tabular}{|c|c|c|c|c|c|c|c|c|}
\hline & \multicolumn{2}{|c|}{ Tension } & \multicolumn{4}{c|}{ Shear } & \multicolumn{2}{c|}{ Compression } \\
\cline { 2 - 9 } Type & $\begin{array}{c}\mathrm{f}_{\mathrm{t}} \\
\left(\mathrm{N} / \mathrm{mm}^{2}\right)\end{array}$ & $\begin{array}{c}\mathrm{G}_{\mathrm{f}}^{\mathbf{I}_{\mathrm{f}}} \\
\left(\mathrm{N} / \mathrm{mm}^{2}\right)\end{array}$ & $\mathrm{c}$ & $\tan \varphi$ & $\tan \Psi$ & $\begin{array}{c}\mathrm{G}_{\mathrm{f}}^{\mathrm{II}_{\mathrm{f}}} \\
\left(\mathrm{N} / \mathrm{mm}^{2}\right)\end{array}$ & $\begin{array}{c}\mathrm{f}_{\mathrm{c}} \\
\left(\mathrm{N} / \mathrm{mm}^{2}\right)\end{array}$ & $\begin{array}{c}\mathrm{G}_{\mathrm{f}}^{\mathbf{c}} \\
\left(\mathrm{N} / \mathrm{mm}^{2}\right)\end{array}$ \\
\hline I & zero & not applicable & zero & 0.65 & 0 & not applicable & 37.0 & 25.0 \\
\hline II and III & 0.05 & 0.01 & 0.1 & 0.4 & 0 & 0.1 & 6.1 & 9.0 \\
\hline
\end{tabular}


Unit (brick,

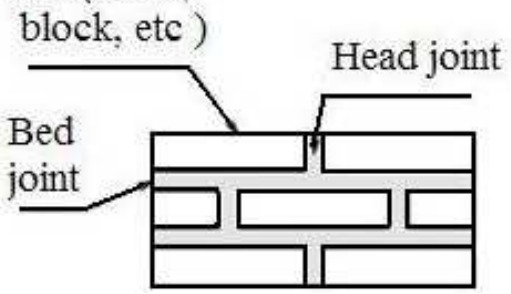

a) Masonry sample

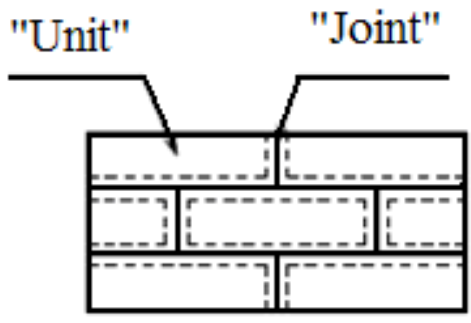

c) Simplified micro-modelling

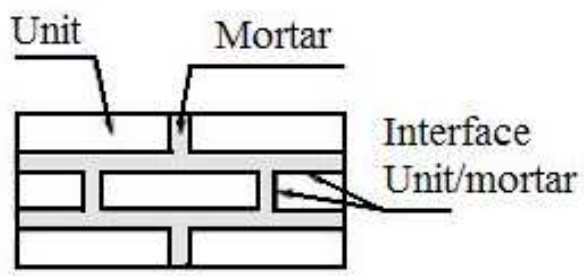

b) Micro-modelling

Figure 1: Micro and macro modelling techniques

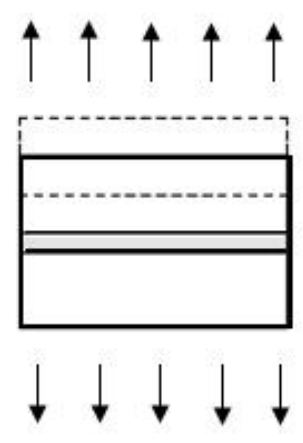

a) Tensile cracking in joint

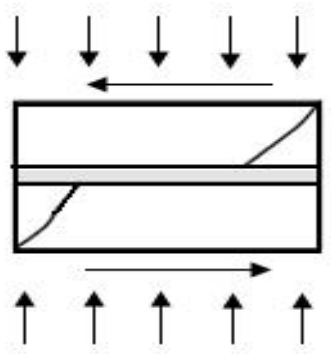

d) Diagonal tensile cracking in the unit

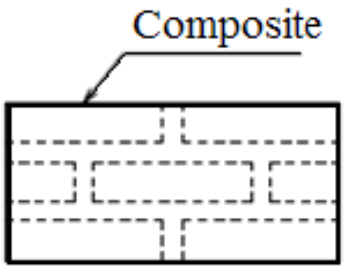

d) Macro-modelling

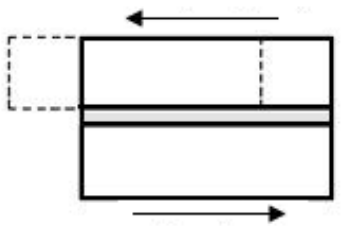

b) Joint slip

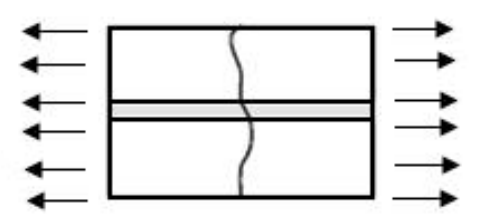

c) Direct tensile cracking in unit

Figure 2: Failure mechanism for masonry 


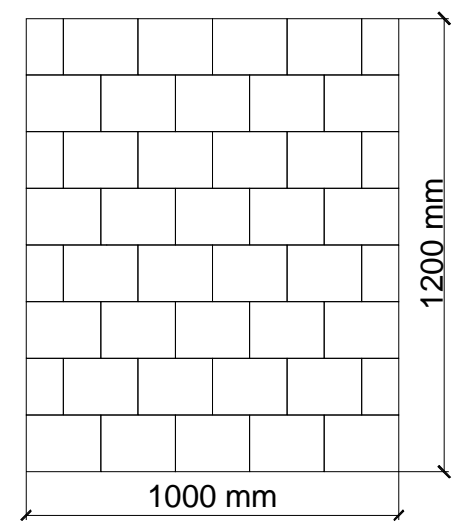

a) Dry stack sawn masonry

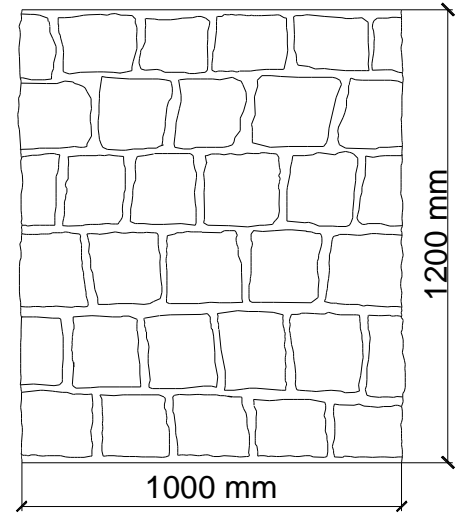

b) Irregular masonry with bonding mortar joints

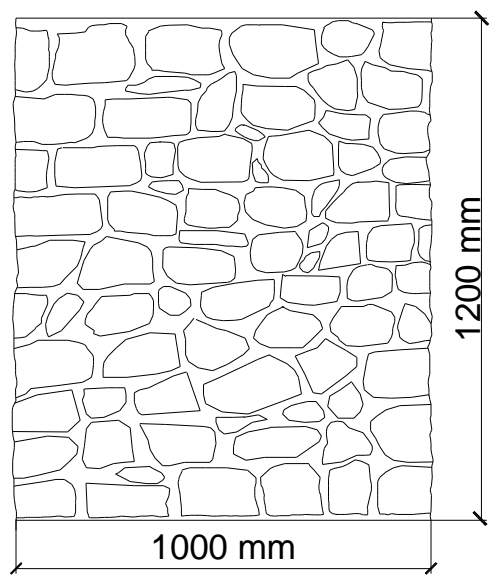

c) Rubble masonry

Figure 3: Details of experimental test specimens 


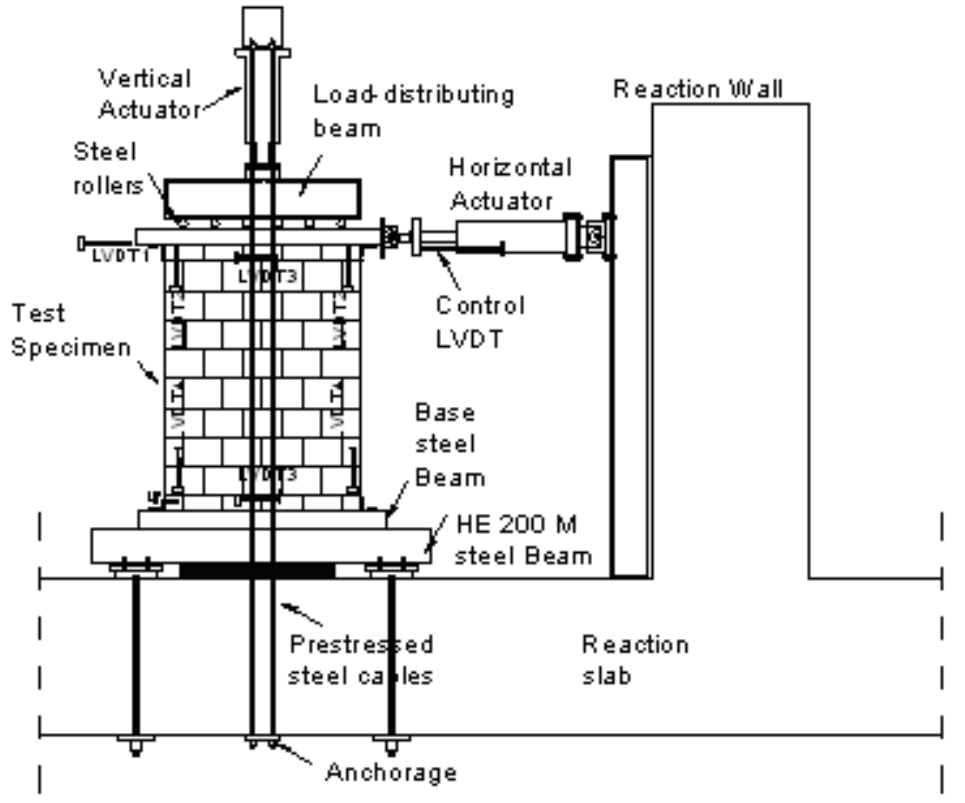

a) Experimental test set-up

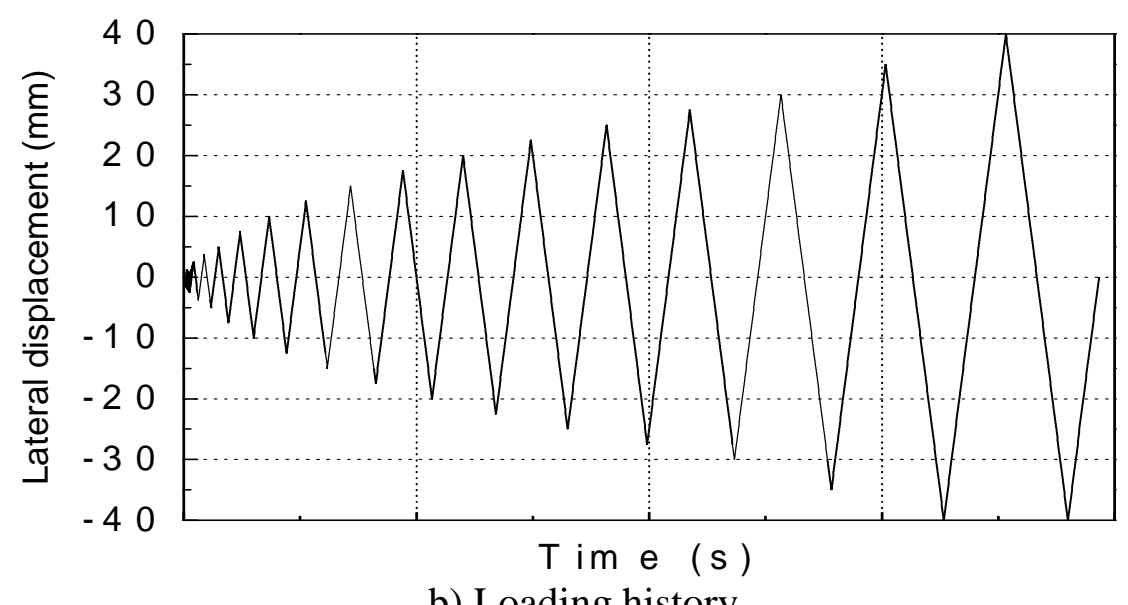

b) Loading history

Figure 4: Experimental test set-up and load history 


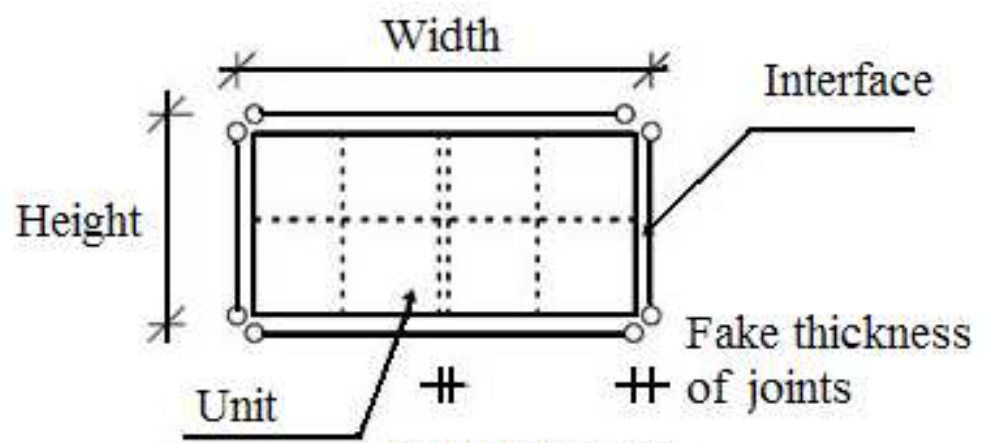

Fake thickness

of cracks

a) Unit and interface around unit

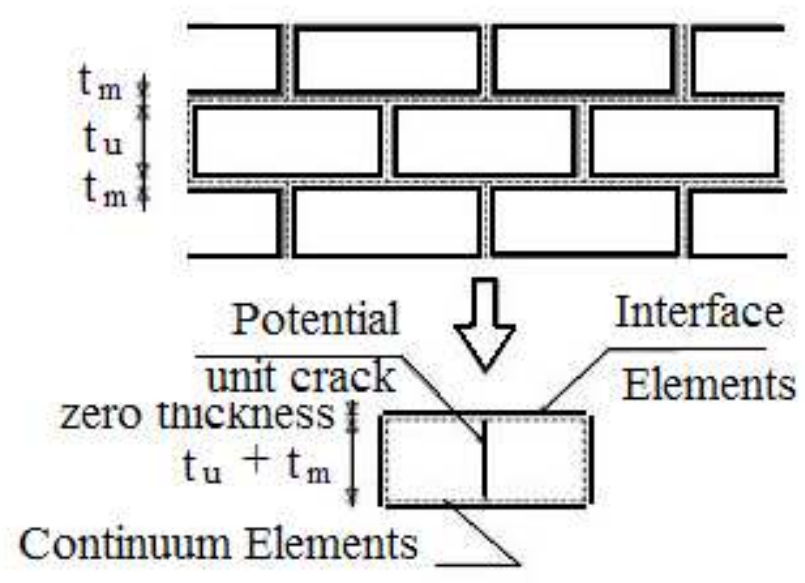

b) Potential crack at the middle of the unit

Figure 5: Mesh generation for swan (regular) dry-stack stone masonry 


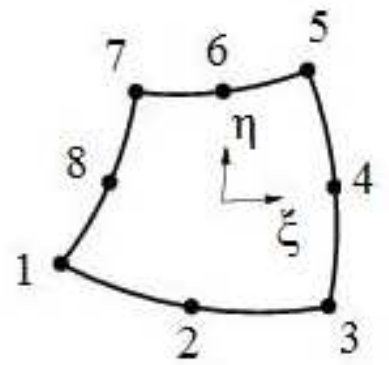

a) Eight nodes continuum plane stress element (cq16m) for units
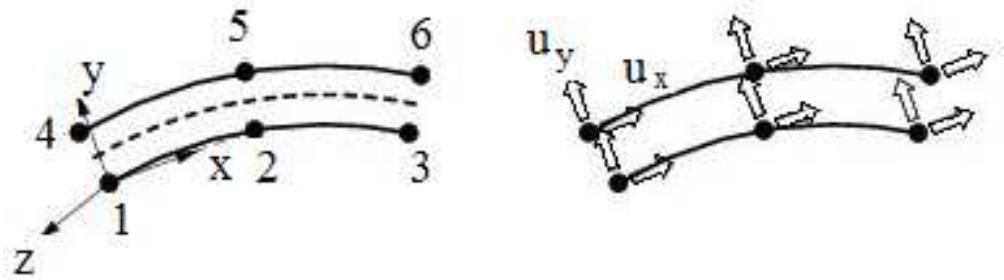

b) Six node zero thickness line interface elements (cl12i) for joints

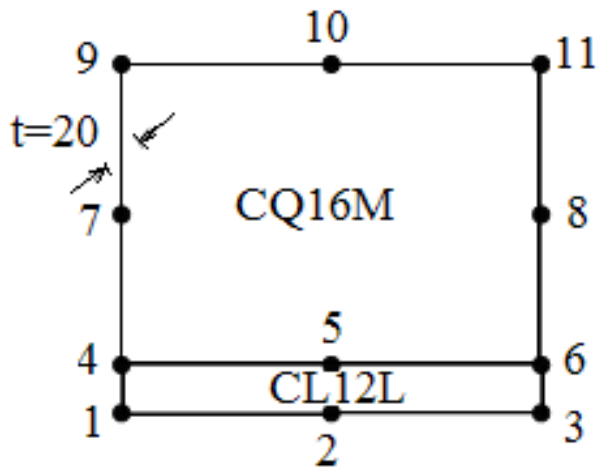

c) Assemblage of cq16m and cl12i elements

Figure 6: Two dimensional elements for units and joints 


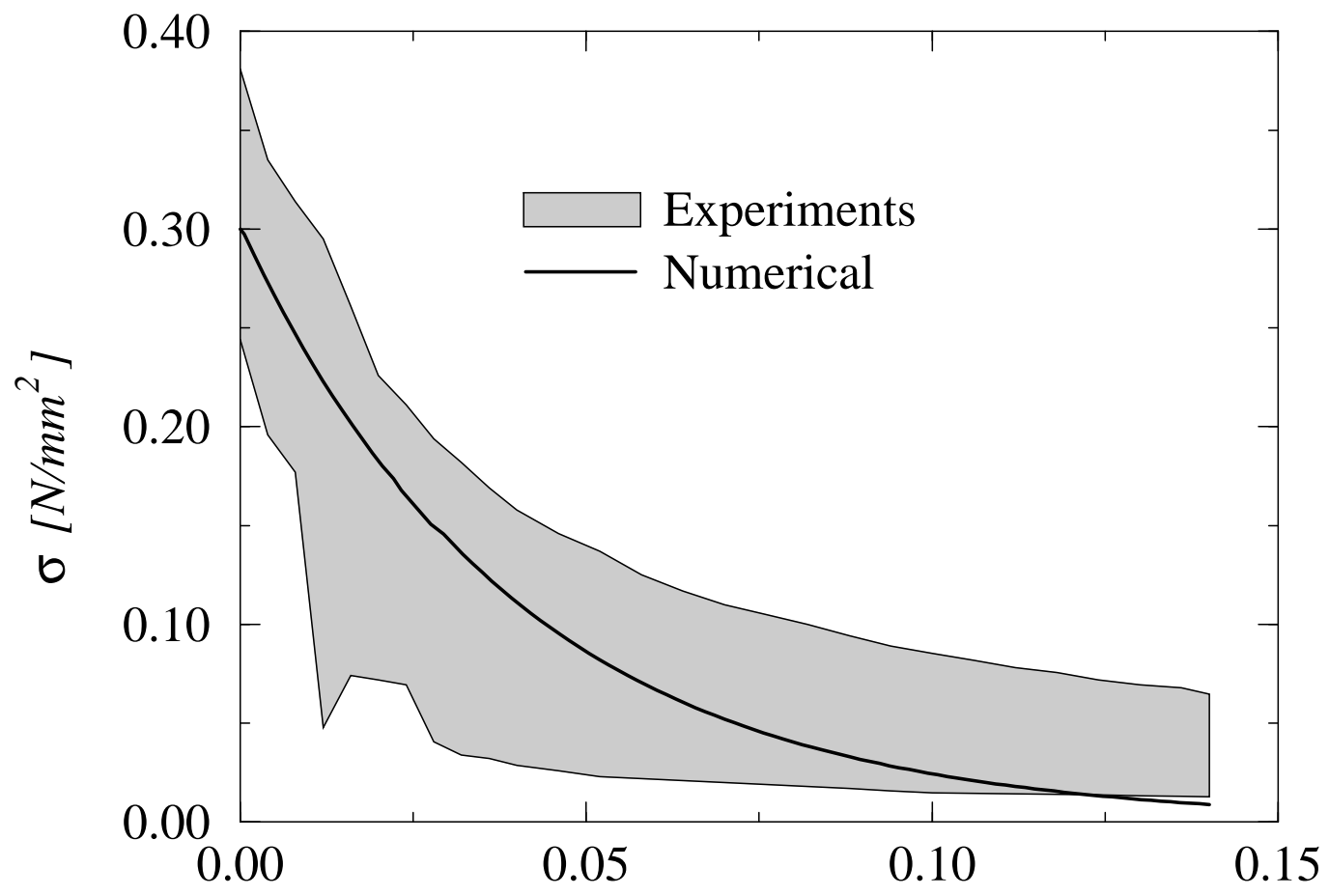

Crack displacement - $\Delta u_{n}[\mathrm{~mm}]$

a) Tension

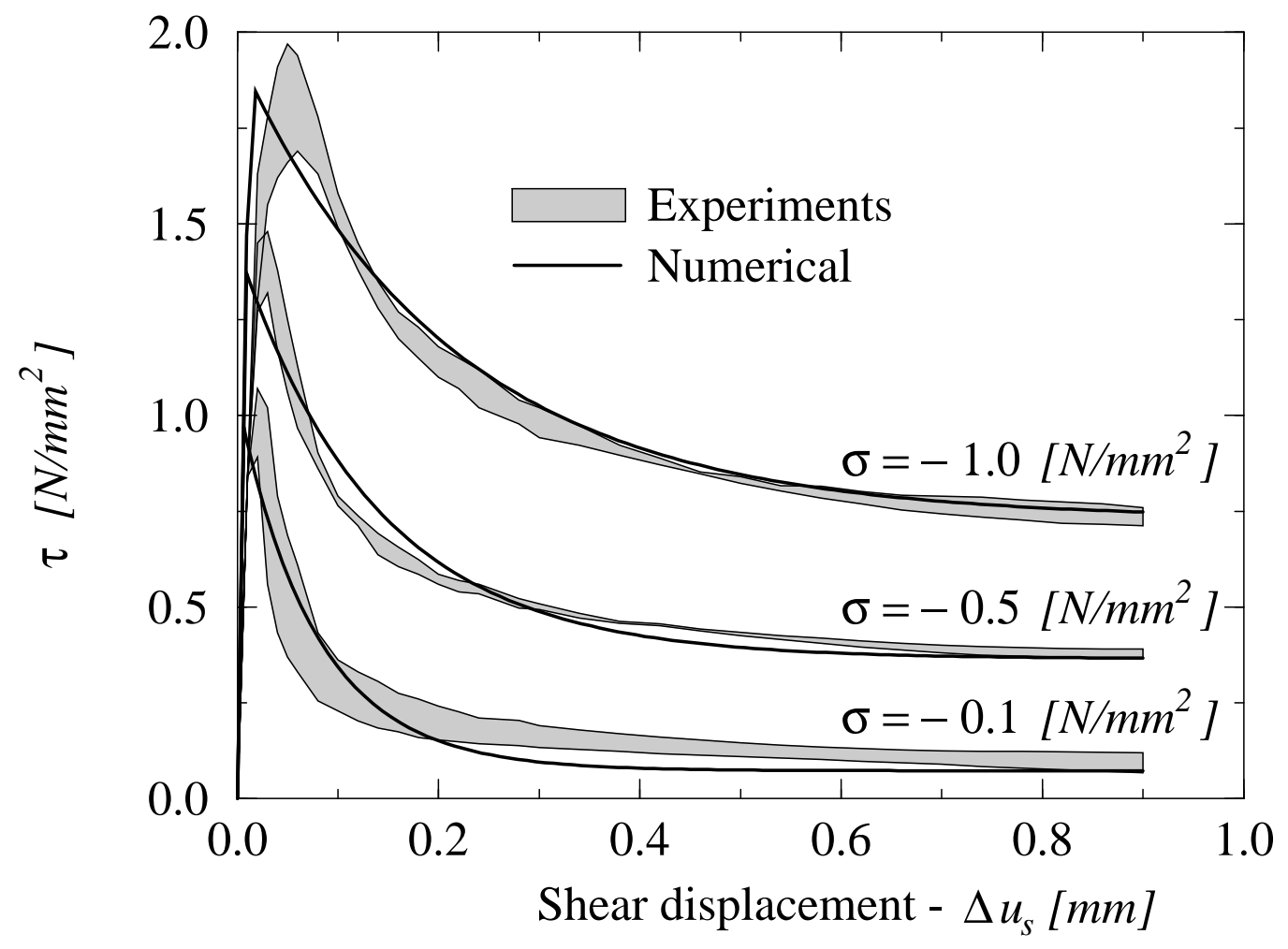

b) Shear 


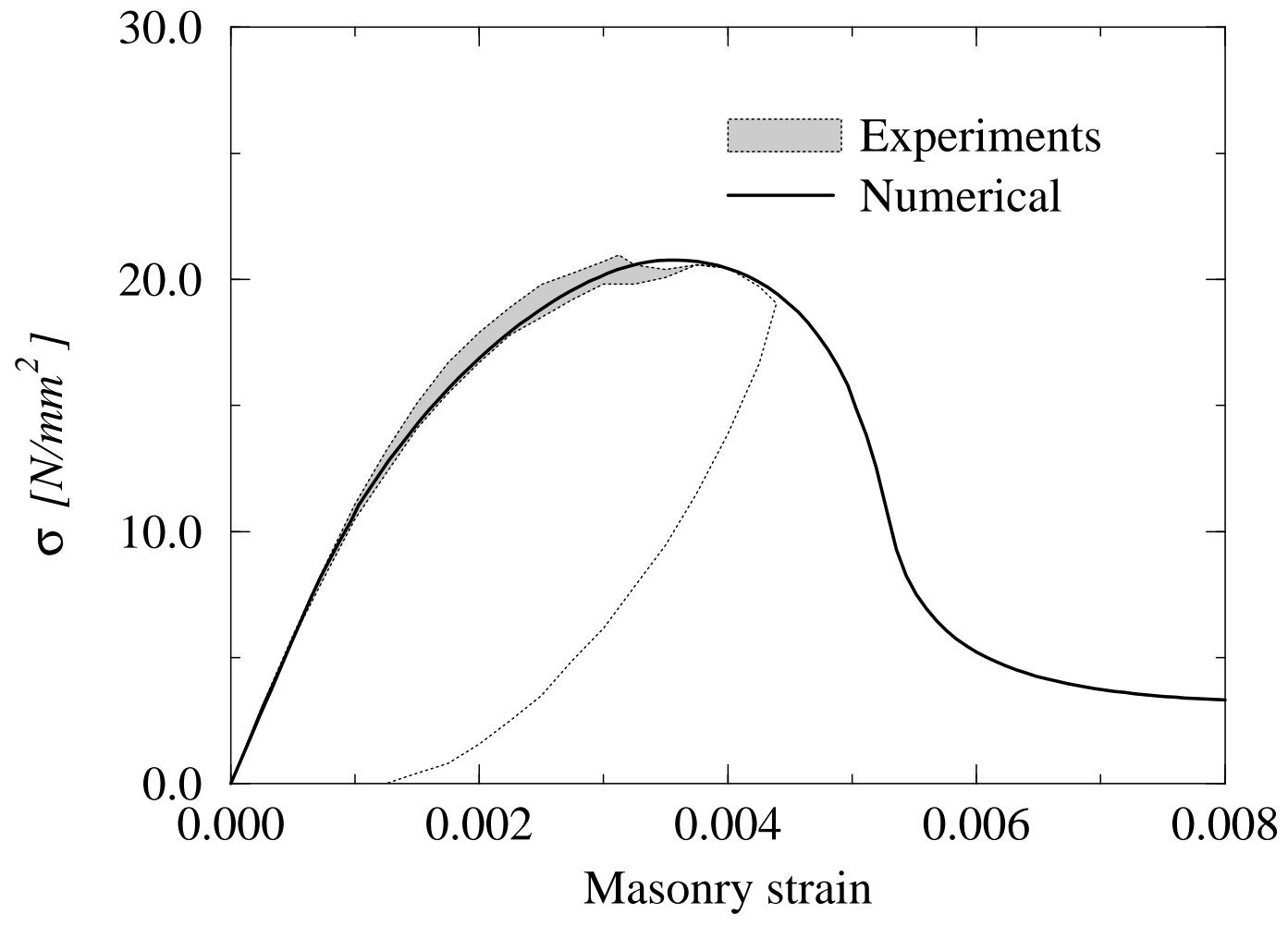

c) Compression

Figure 7: Inelastic behaviour of interface model and validation with experiments, Lourenço and Rots (1997) 


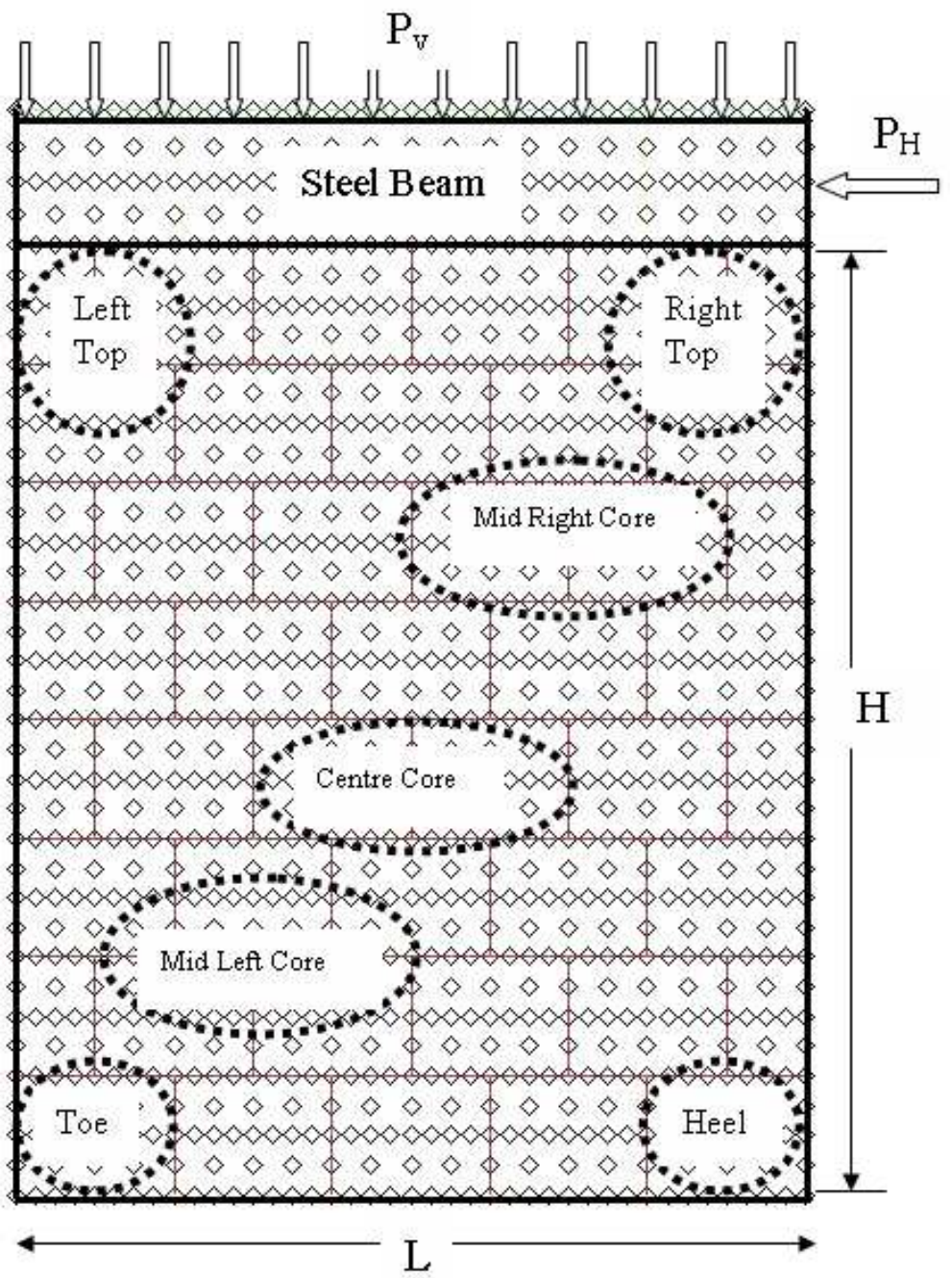

Figure 8: Critical regions in masonry shear wall 


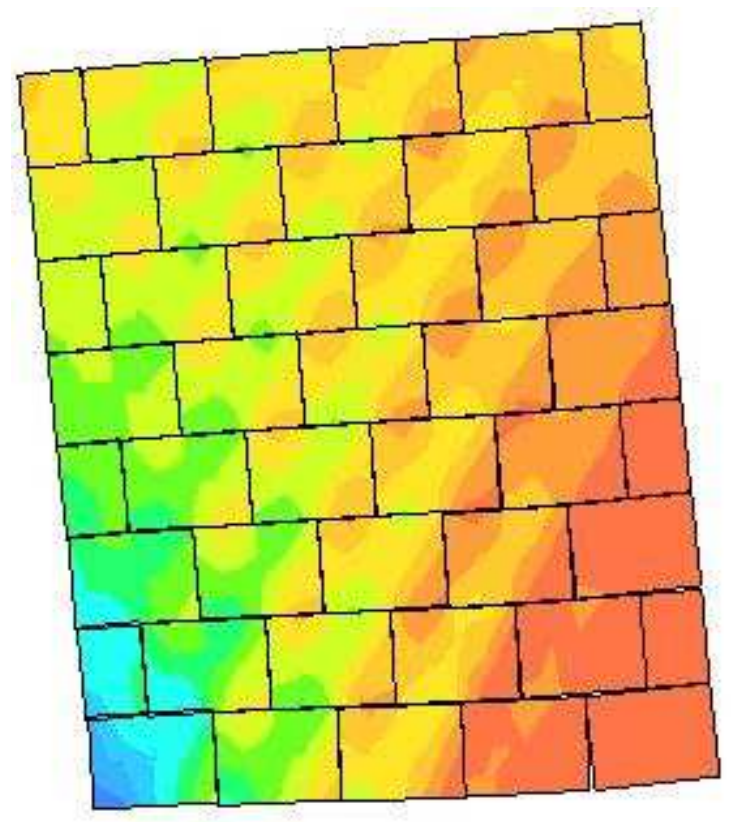

i) At $2.5 \mathrm{~mm}$ lateral displacement

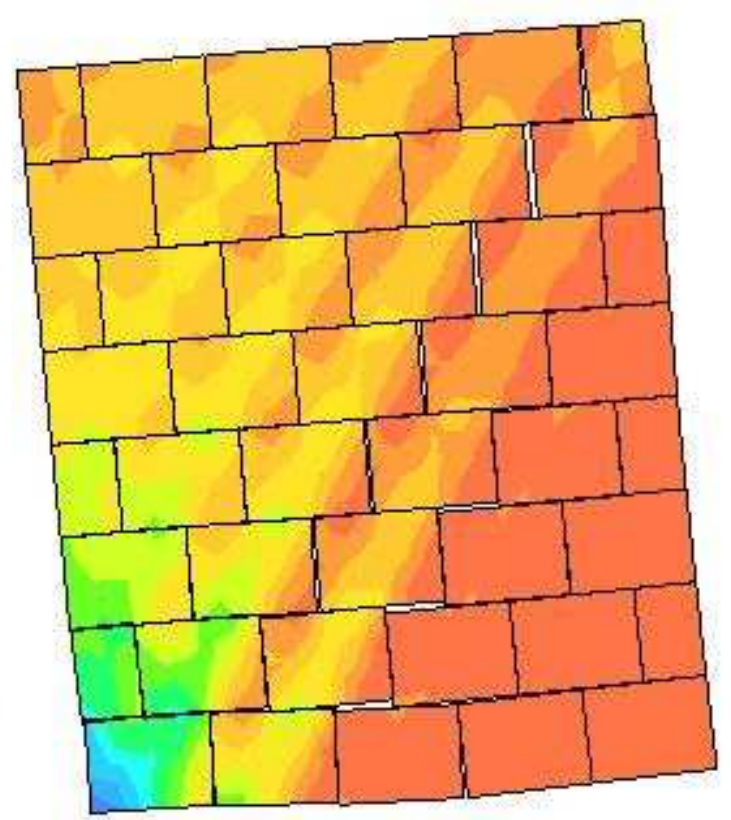

ii) At $5 \mathrm{~mm}$ lateral displacement

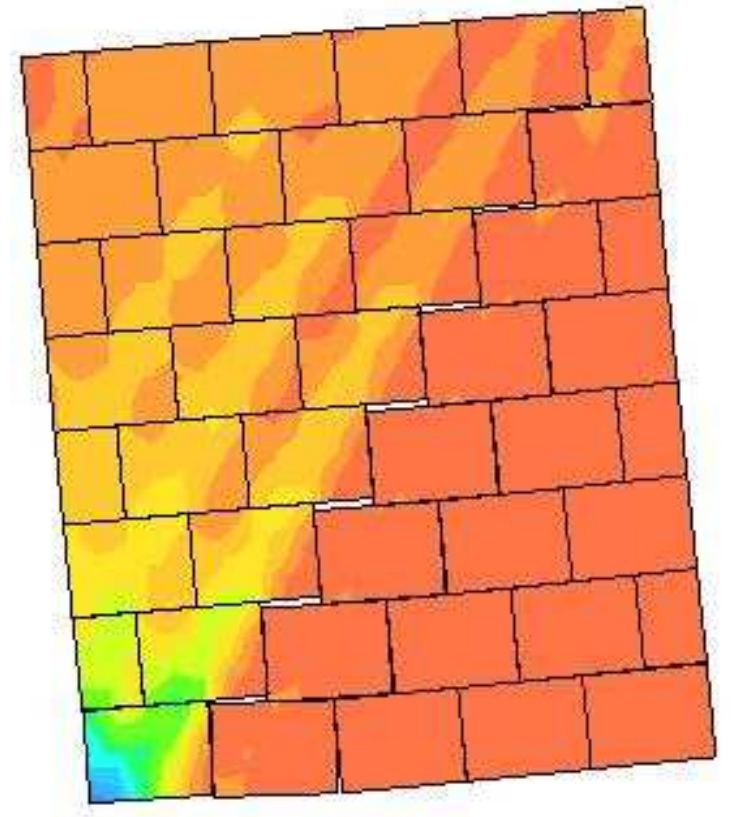

iii) At $10 \mathrm{~mm}$ lateral displacement

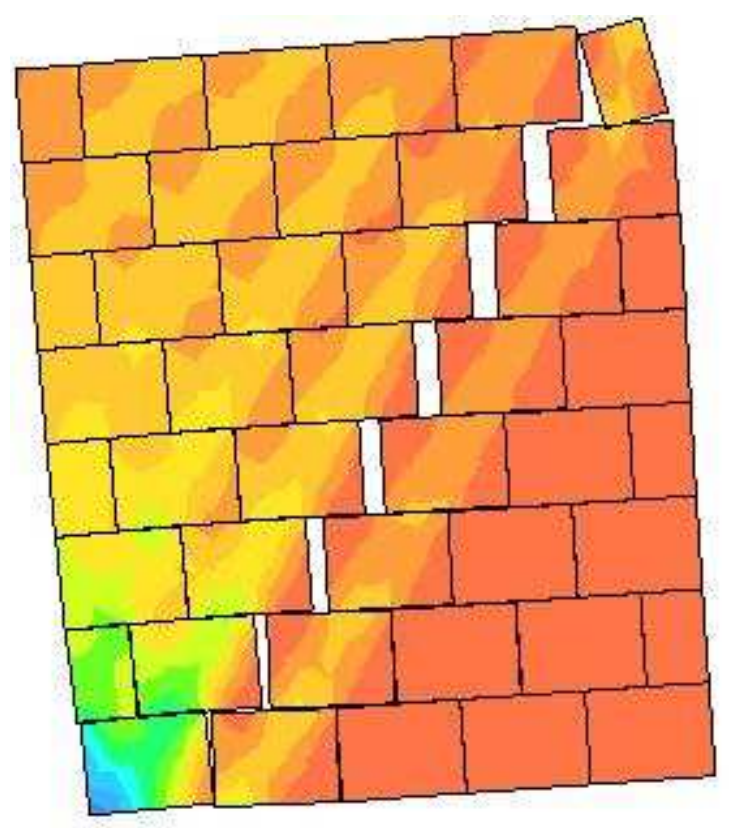

iv) At $30 \mathrm{~mm}$ lateral displacement

a) Deformation progress of Type I, Sawn masonry under $175 \mathrm{kN}$ 


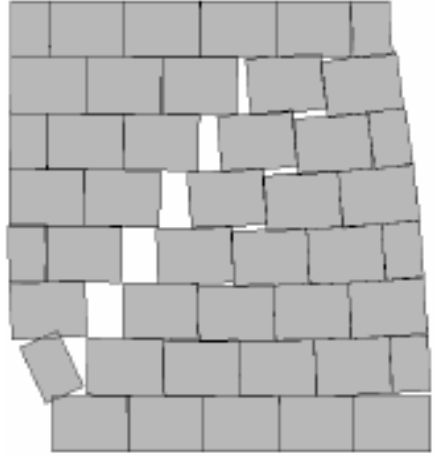

i) Numerical

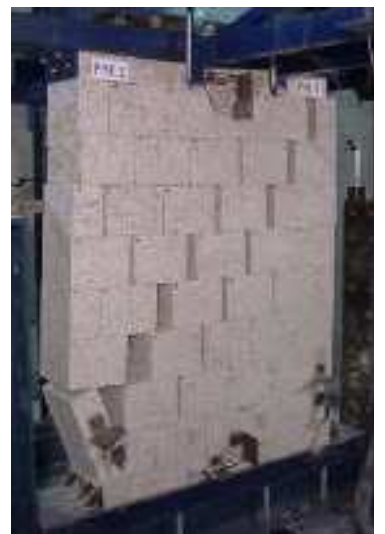

ii) Experimental

b) Incremental deformed mesh at collapse $(175 \mathrm{kN})$ and experimental failure

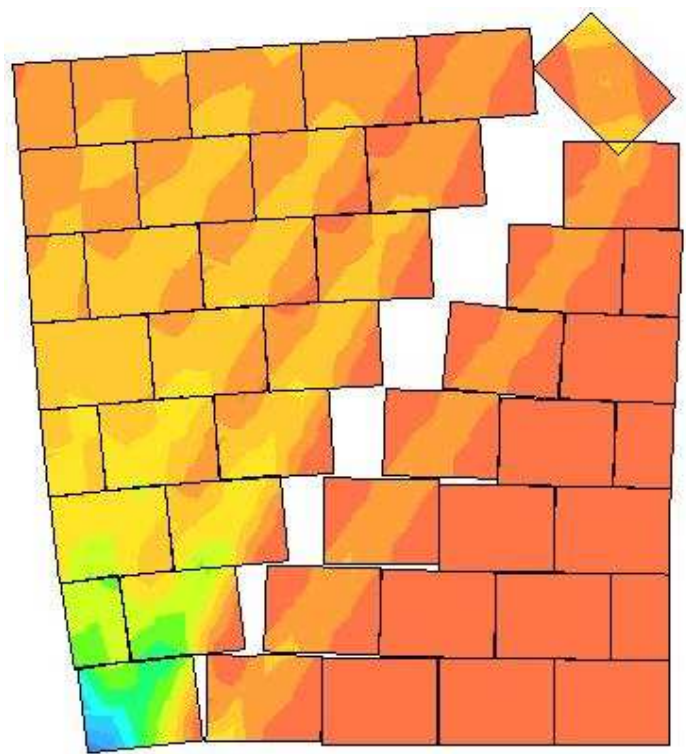

i) Numerical

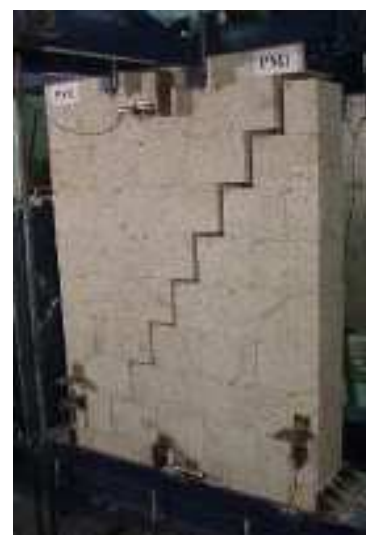

ii) Experimental

c) Incremental deformed mesh at collapse $(250 \mathrm{kN})$ and experimental failure

Figure 9: Deformation progress of type I, Sawn masonry 


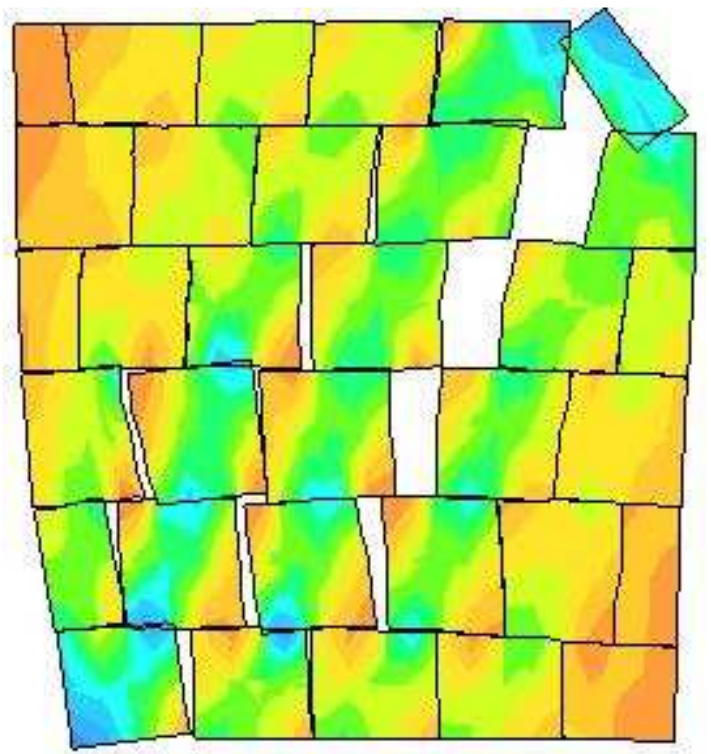

i) Numerical failure

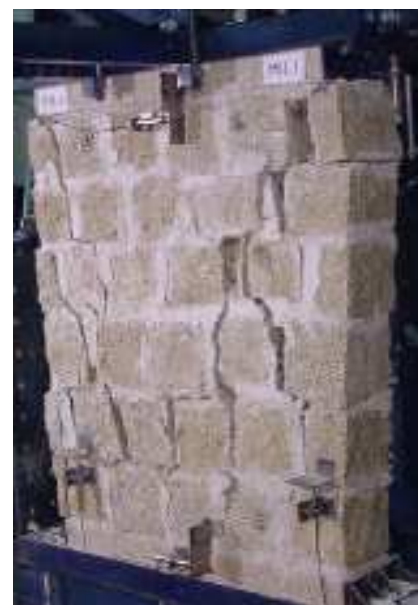

ii) Experimental failure

Figure 10: Deformed shape of Type II, Irregular masonry at collapse 


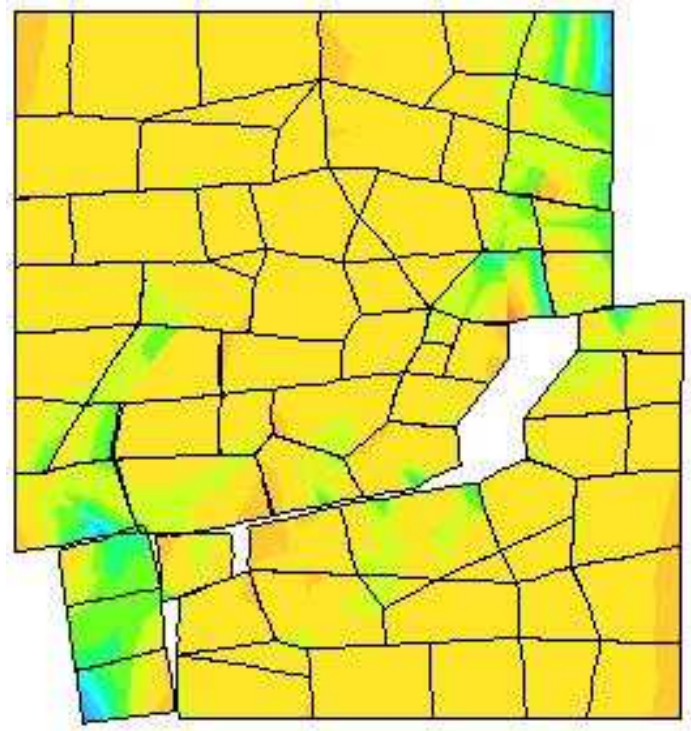

i) Numerical failure mode

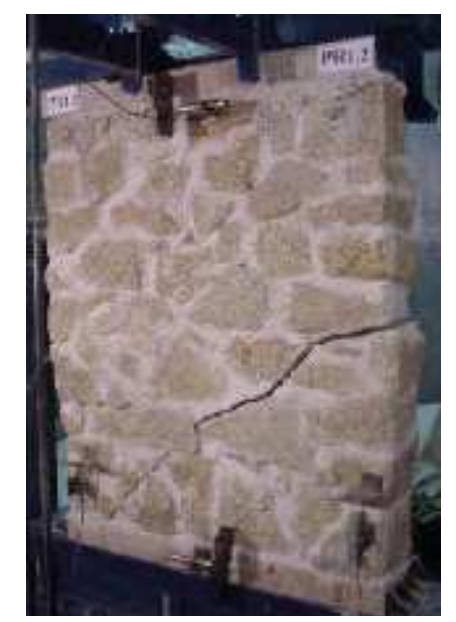

ii) Experimental failure mode

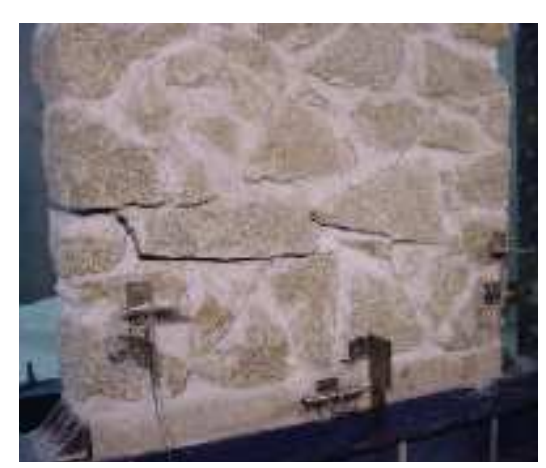

iii) Experimental failure mode

a) Deformed shape of original mesh 


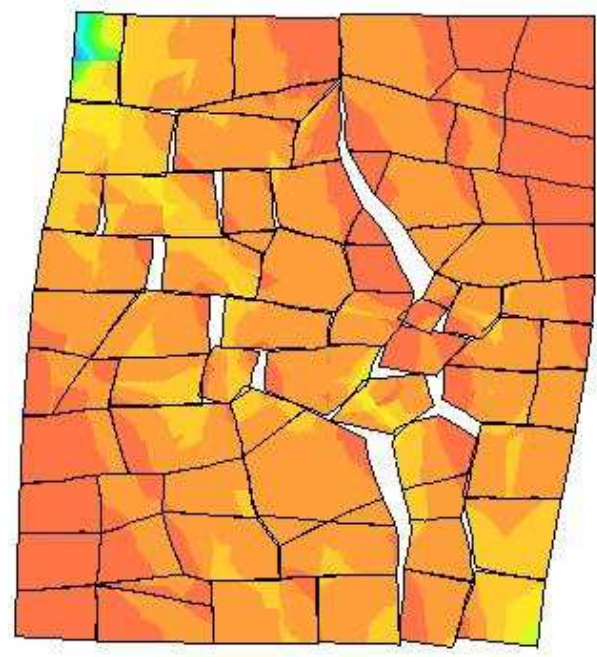

Loading at top left corner (L-R)

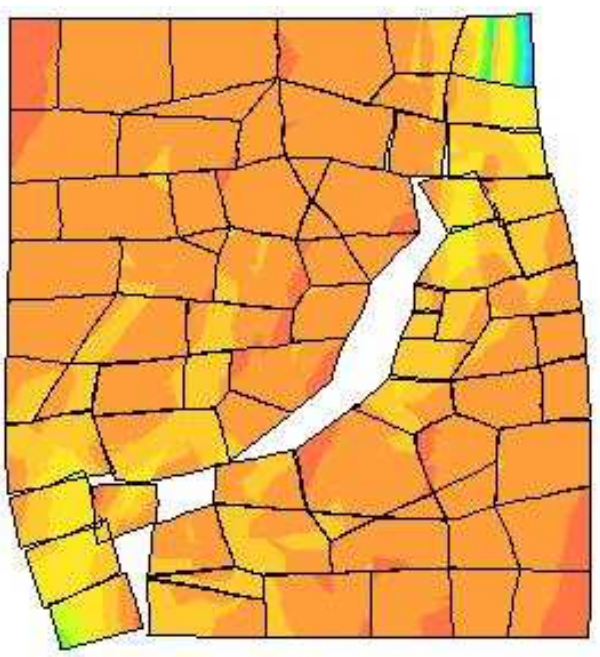

Loading at top right corner (R-L)

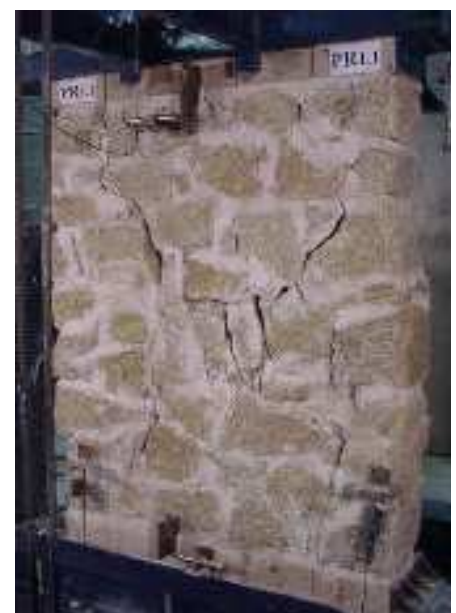

Experimental failure modes

i) Axial pre-compression $=100 \mathrm{kN}$ 


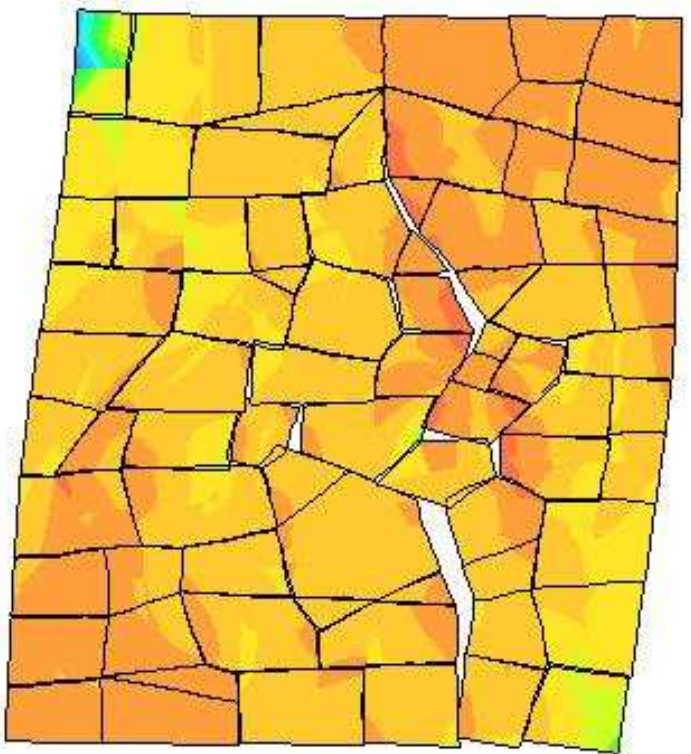

Loading at top left corner (L-R)

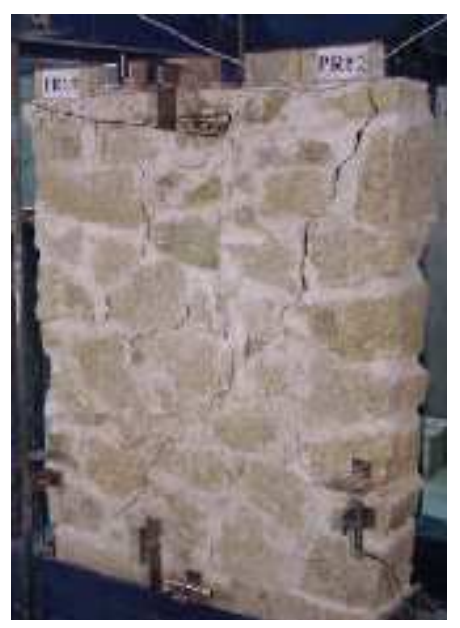

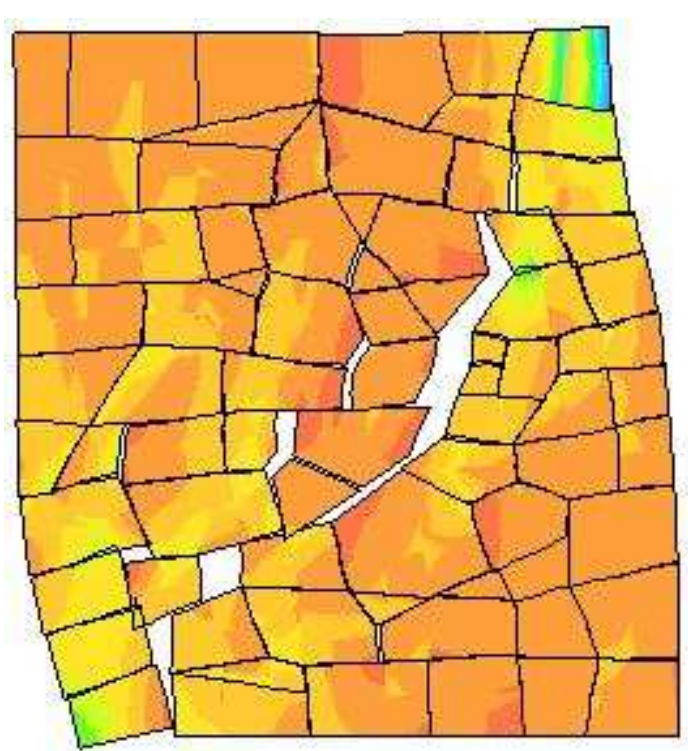

Loading at top right corner (R-L)

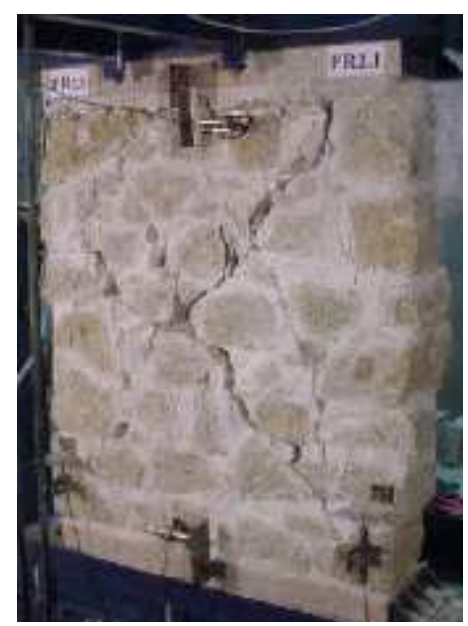

Experimental failure modes

ii) Axial pre-compression $=175 \mathrm{kN}$ 


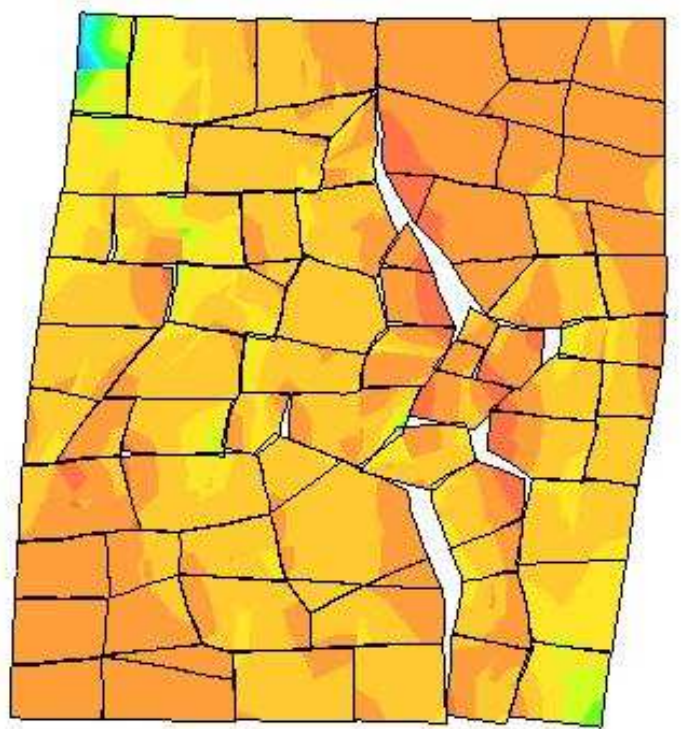

Loading at top left corner (L-R)

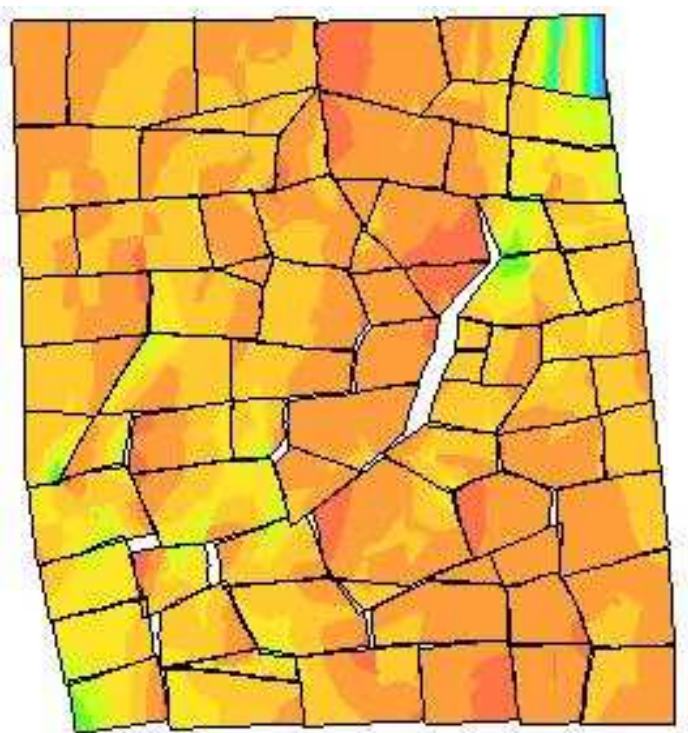

Loading at top right corner (R-L)

iii) Axial pre-compression $=250 \mathrm{kN}$

b) Deformed shape of modified mesh

Figure 11: Deformed shape of original and modified mesh of Type III, Rubble masonry 


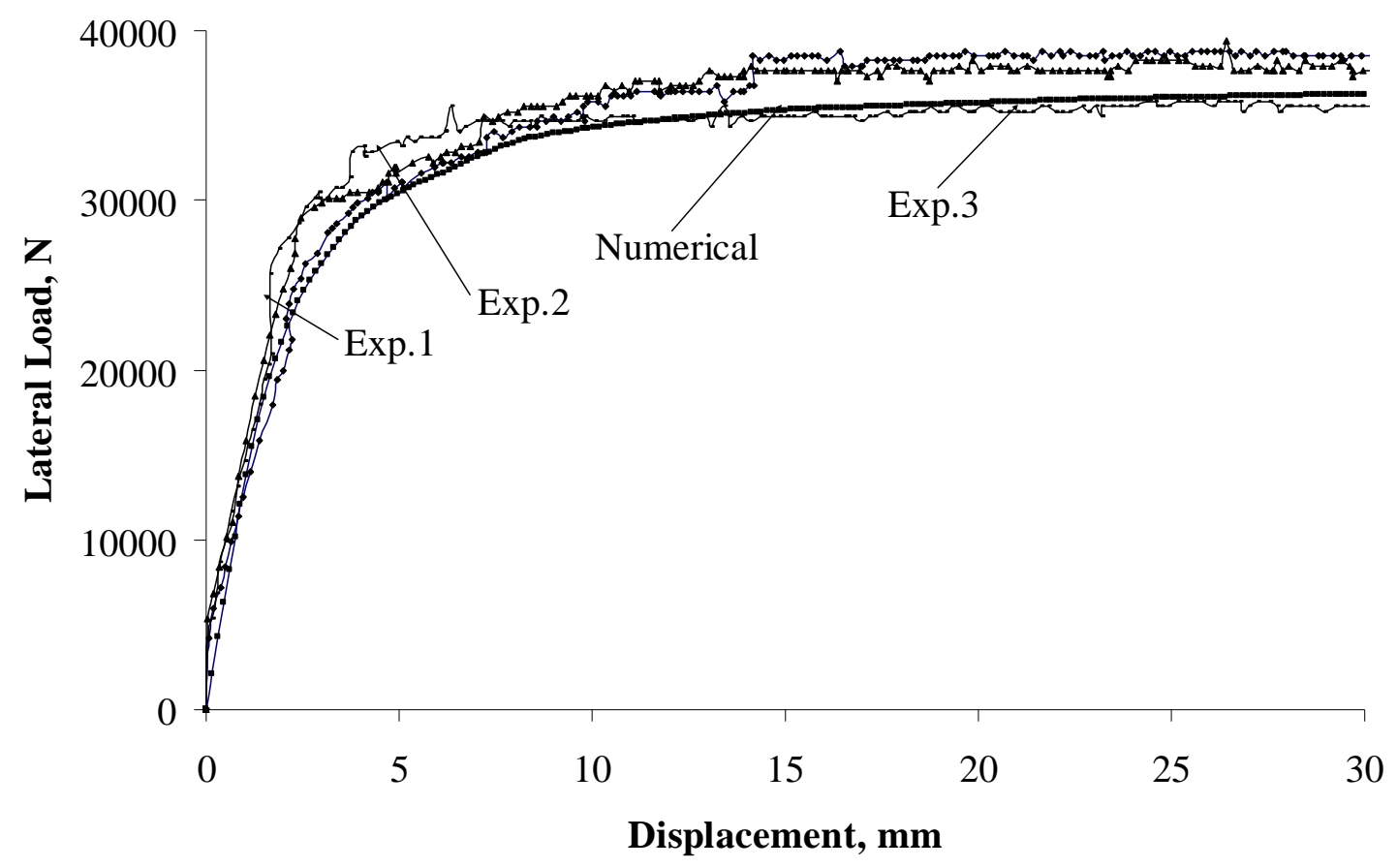

a) Axial pre-compression load $=100 \mathrm{kN}$

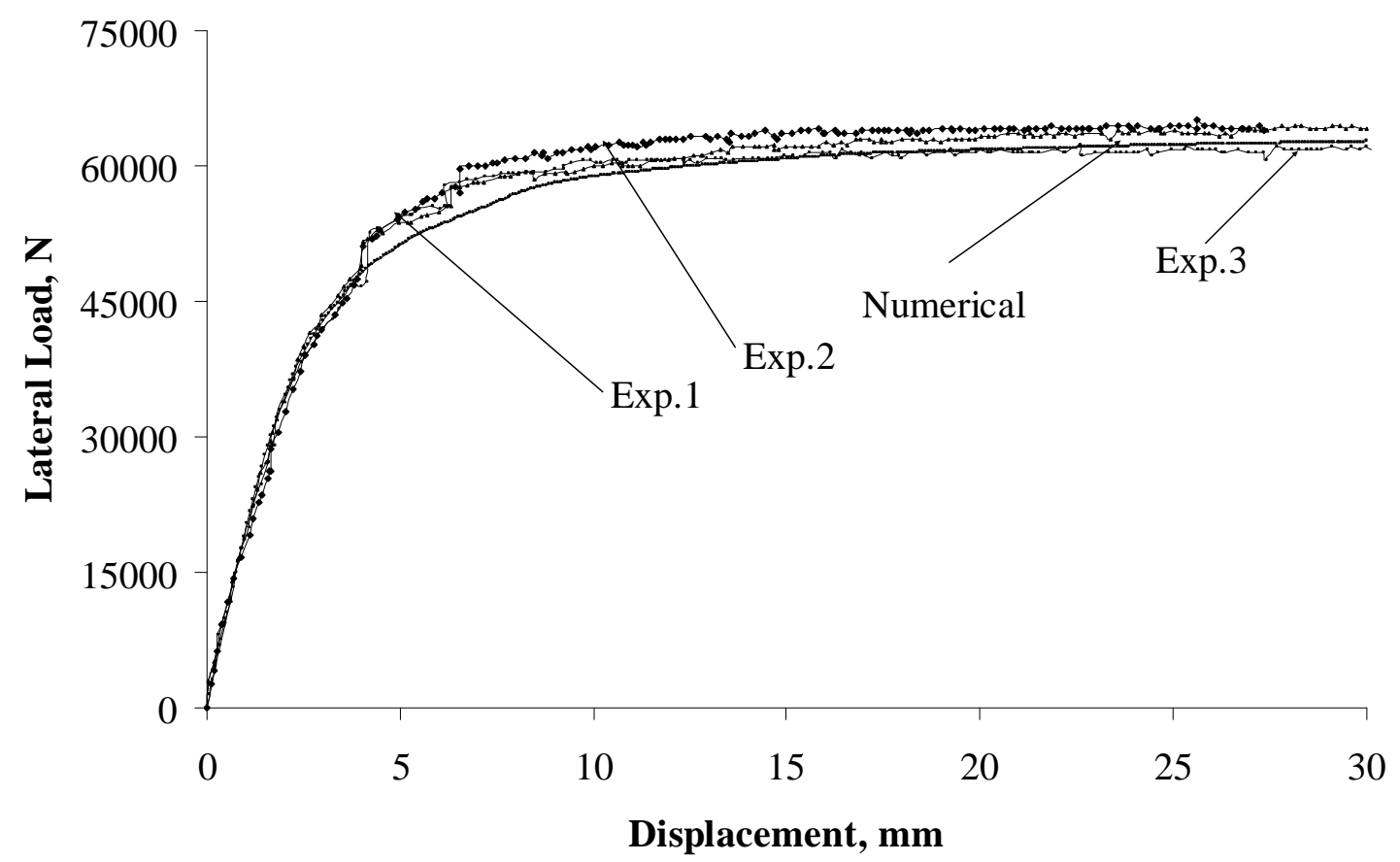

b) Axial pre-compression load $=175 \mathrm{kN}$ 


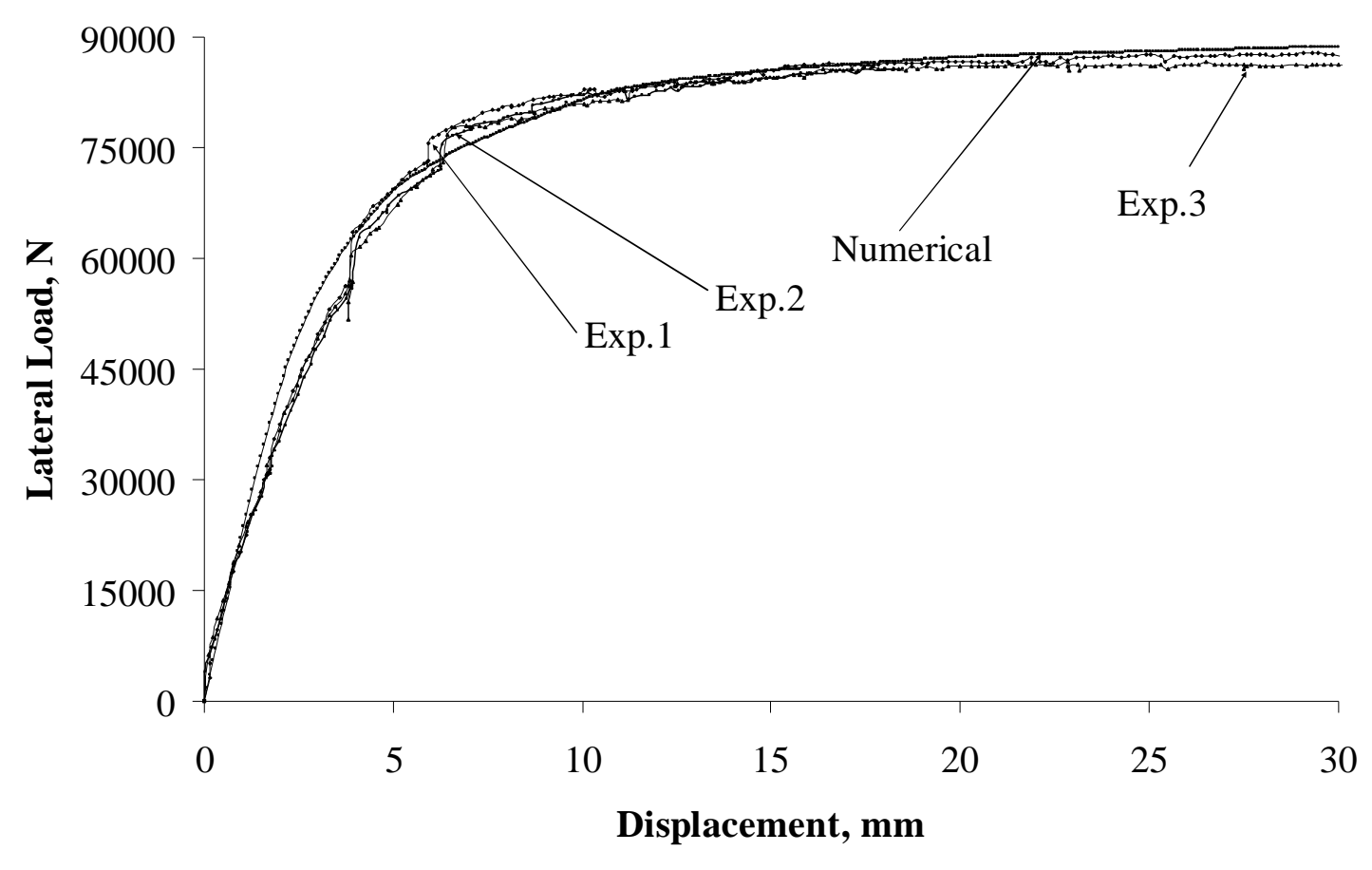

c) Axial pre-compression load $=250 \mathrm{kN}$

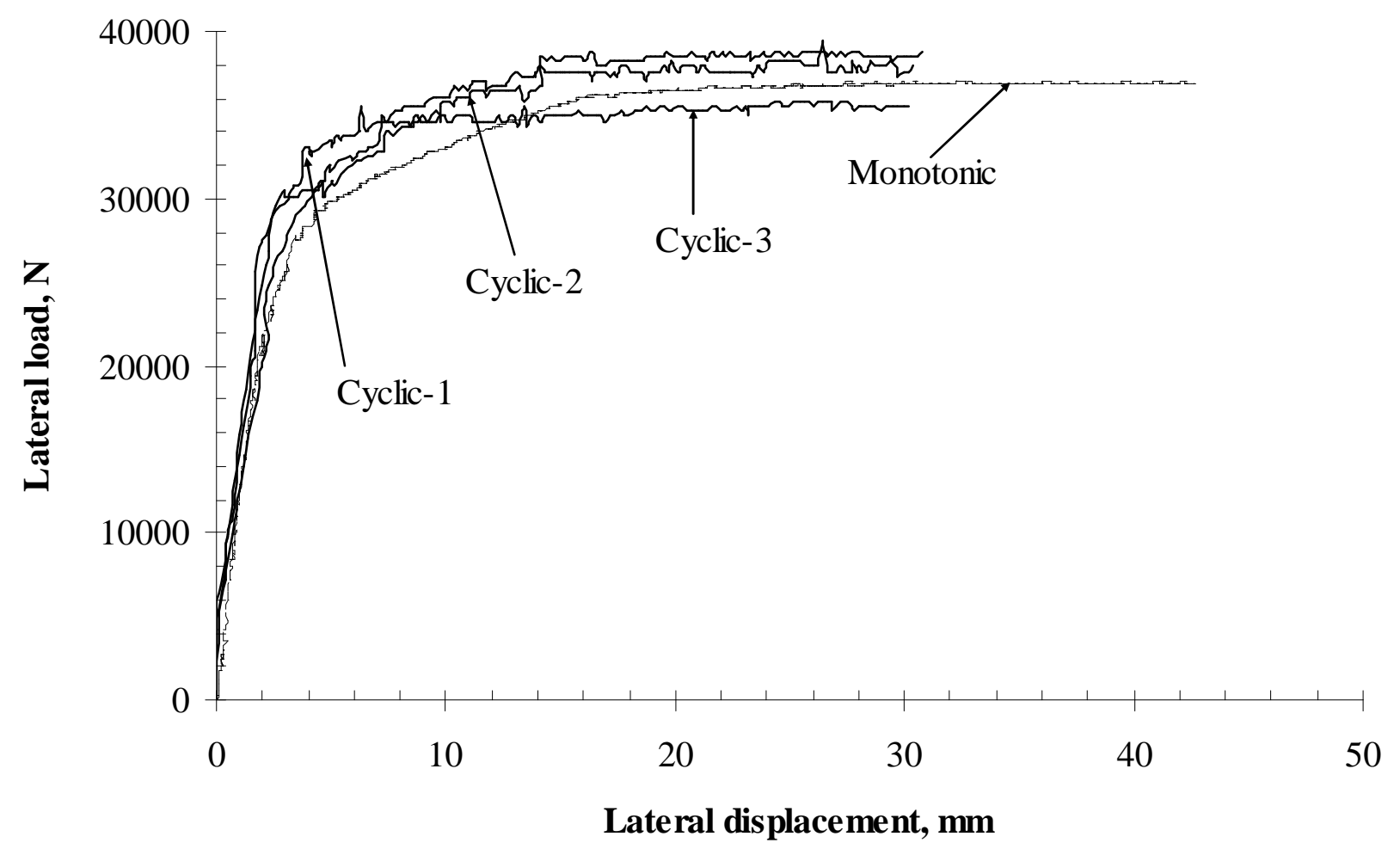

d) Comparison of Envelopes of Monotonic and Cyclic Loading (100 kN) 


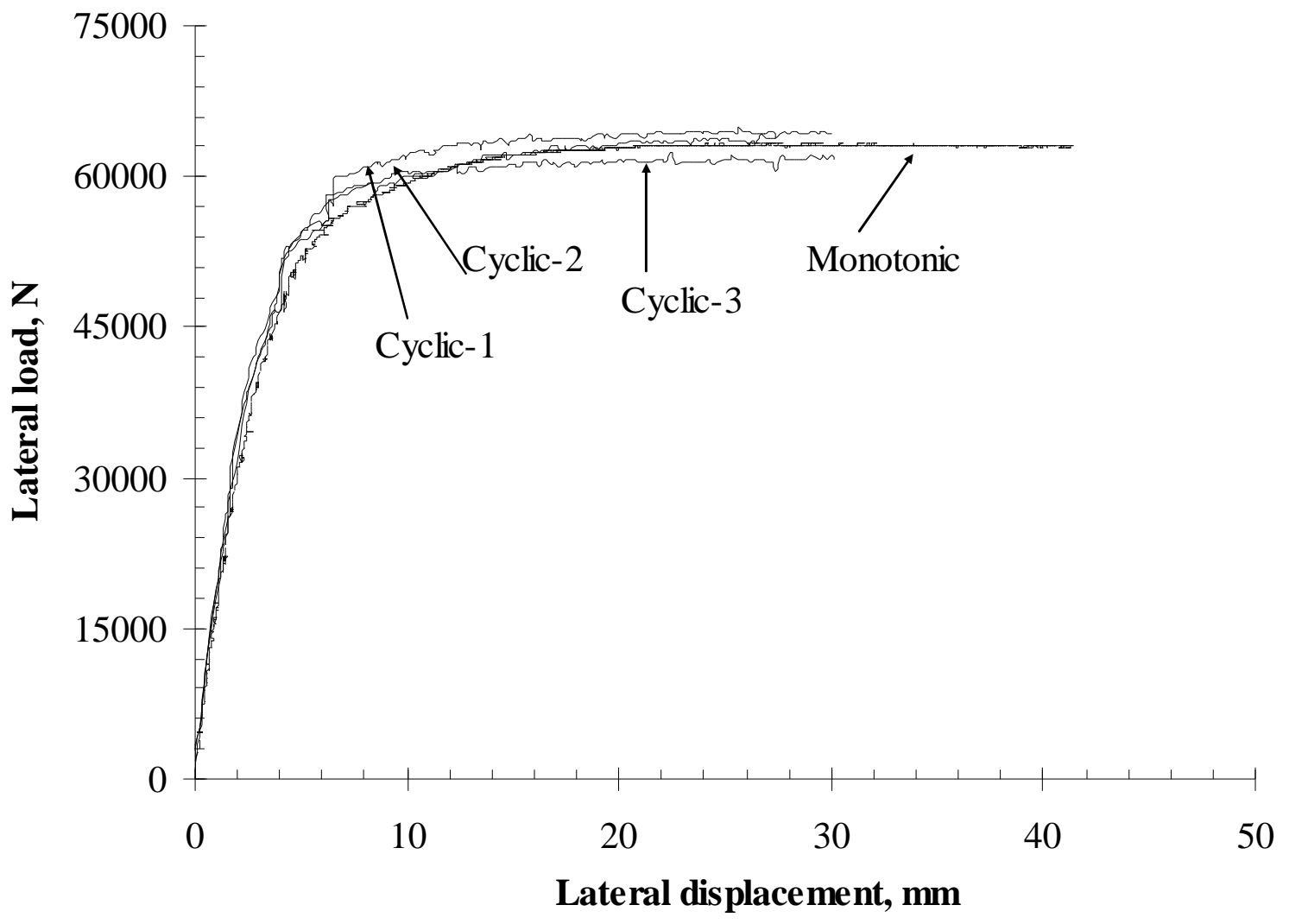

e) Comparison of Envelopes of Monotonic and Cyclic Loading (175 kN)

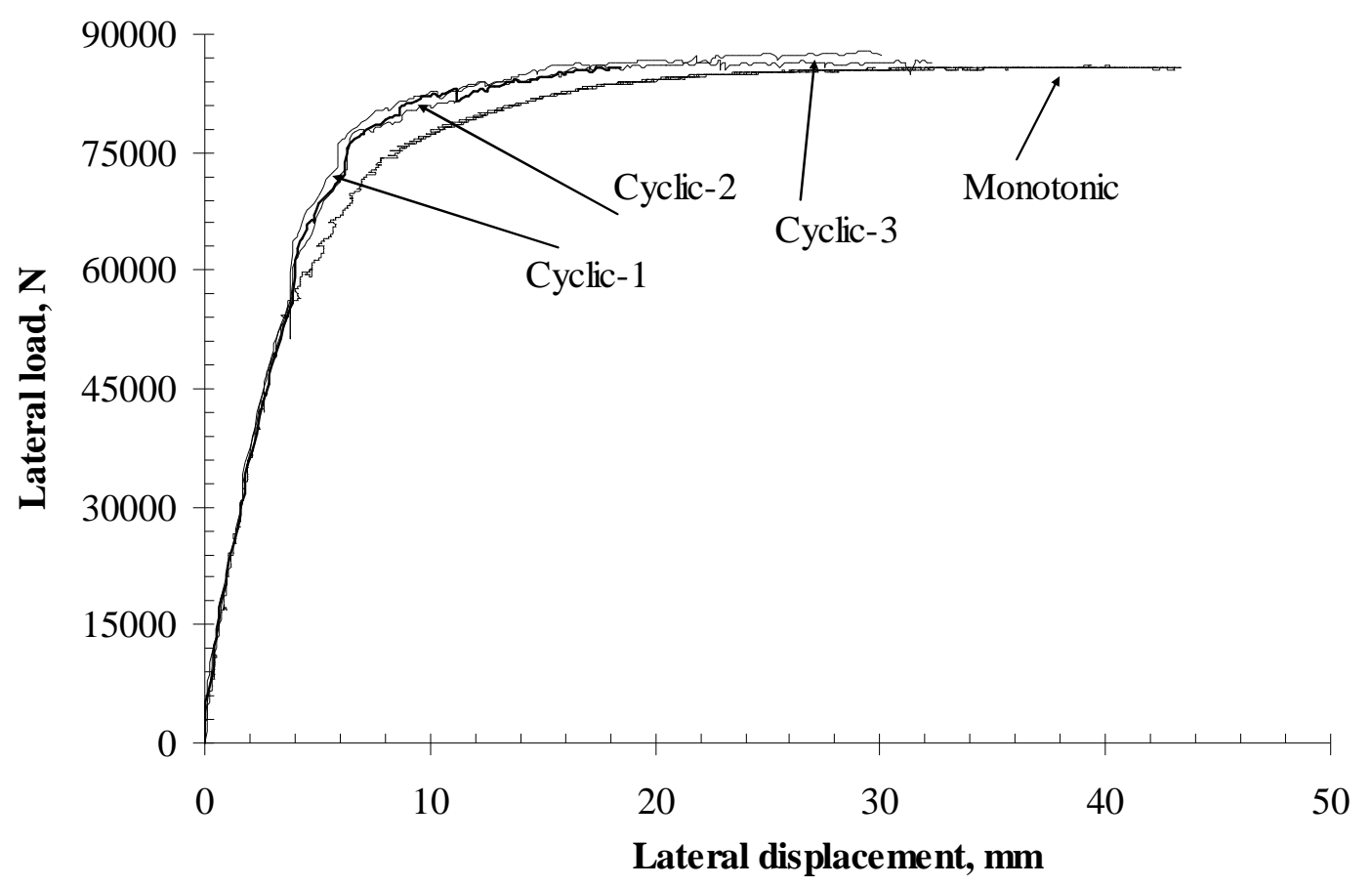

f) Comparison of Envelopes of Monotonic and Cyclic Loading (250 kN)

Figure 12: Load-displacement envelope curves of Type I, Sawn stone masonry 


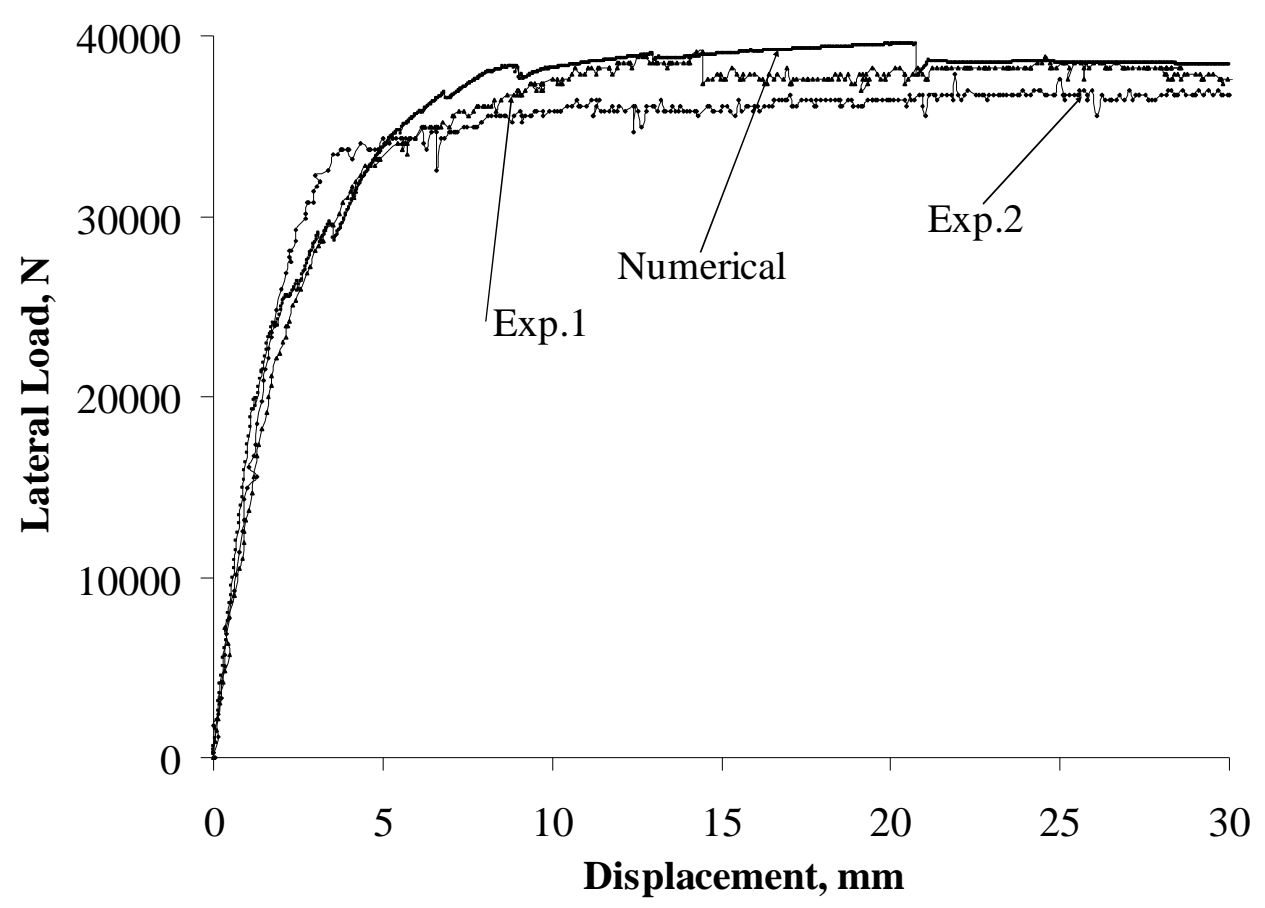

a) Axial pre-compression load $=100 \mathrm{kN}$

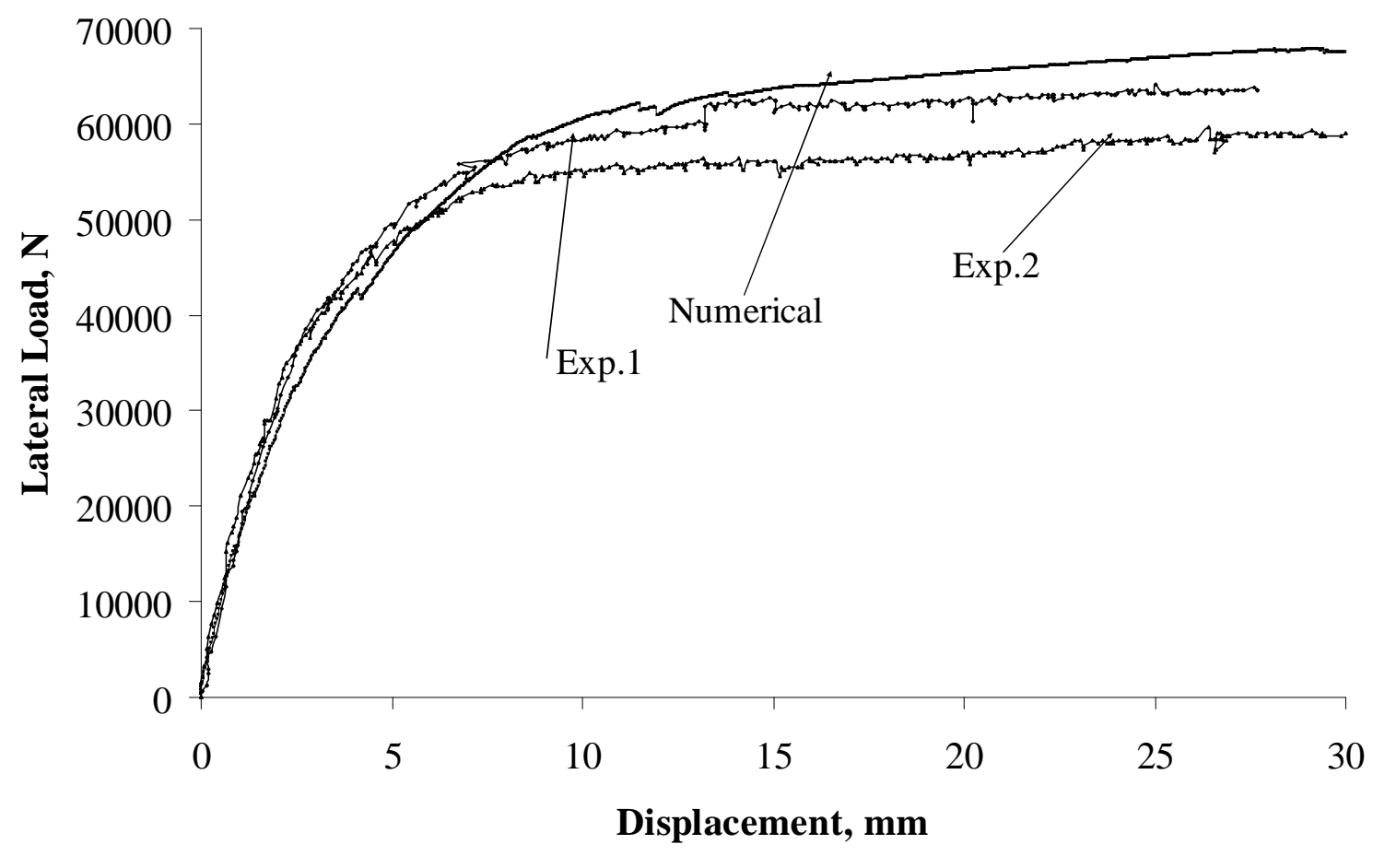

b) Axial pre-compression load $=175 \mathrm{kN}$ 


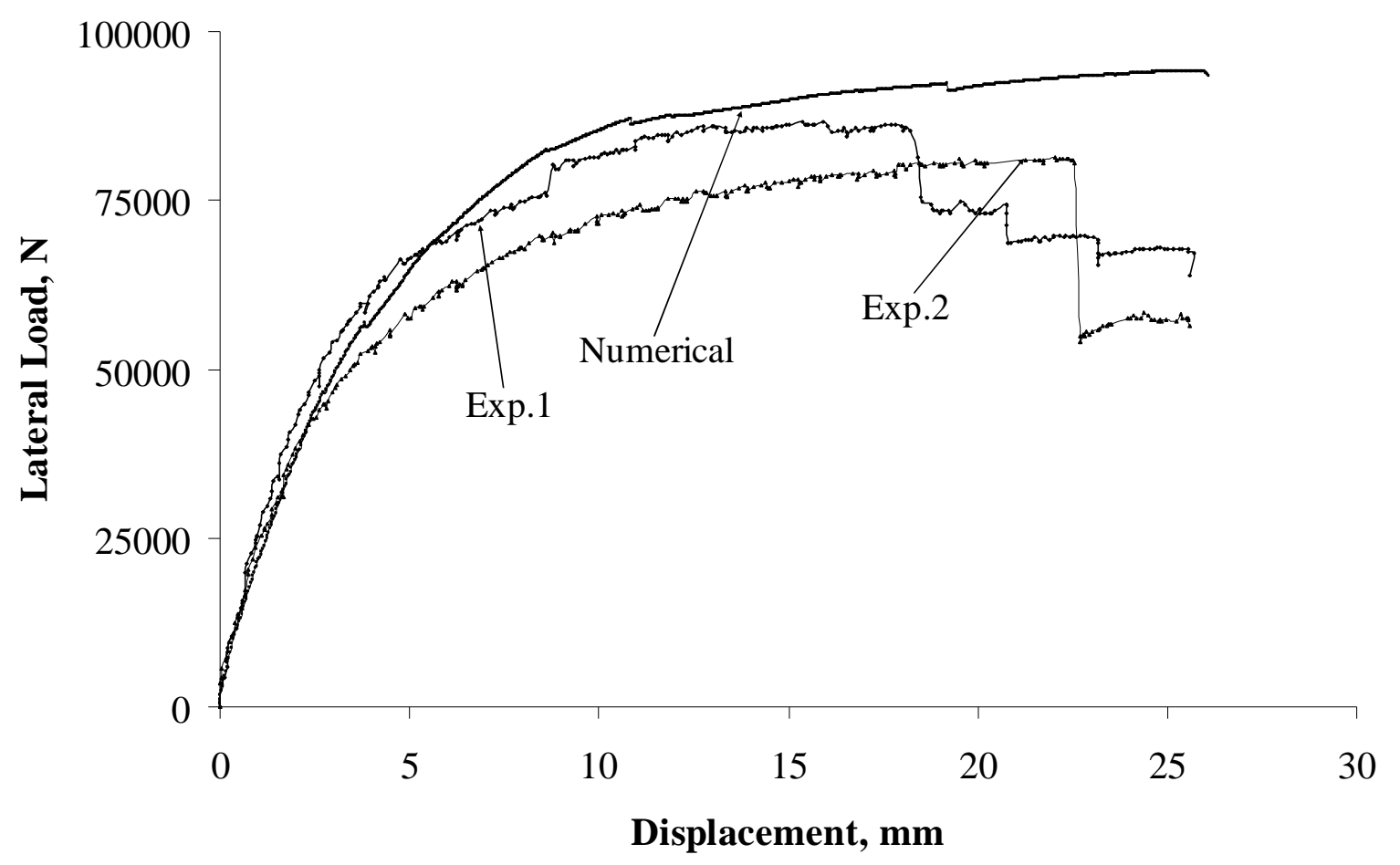

c) Axial pre-compression load $=250 \mathrm{kN}$

Figure 13: Load-displacement envelope curves of Type II, Irregular stone masonry 


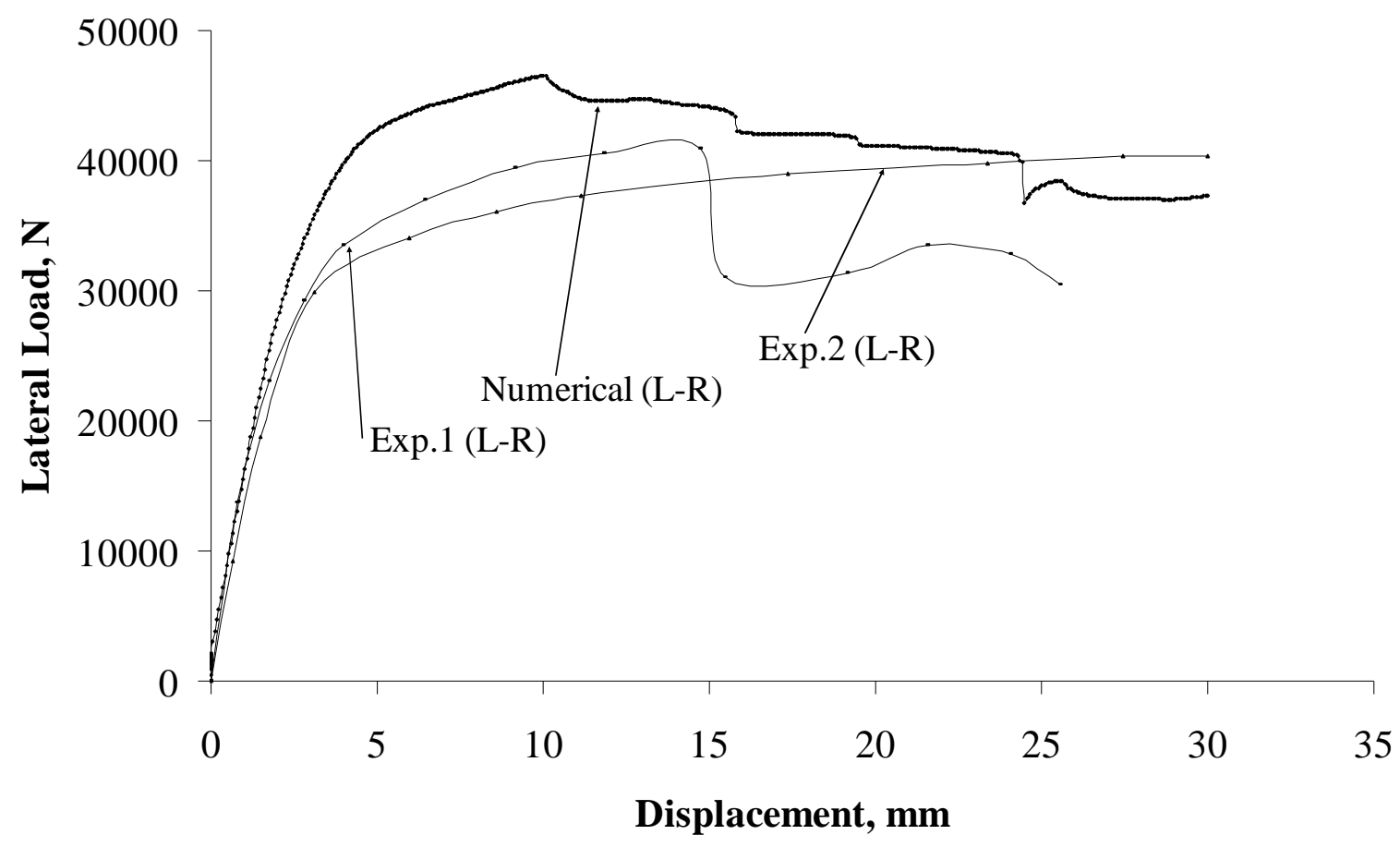

i) Loading at top left corner (Left to Right (L-R))

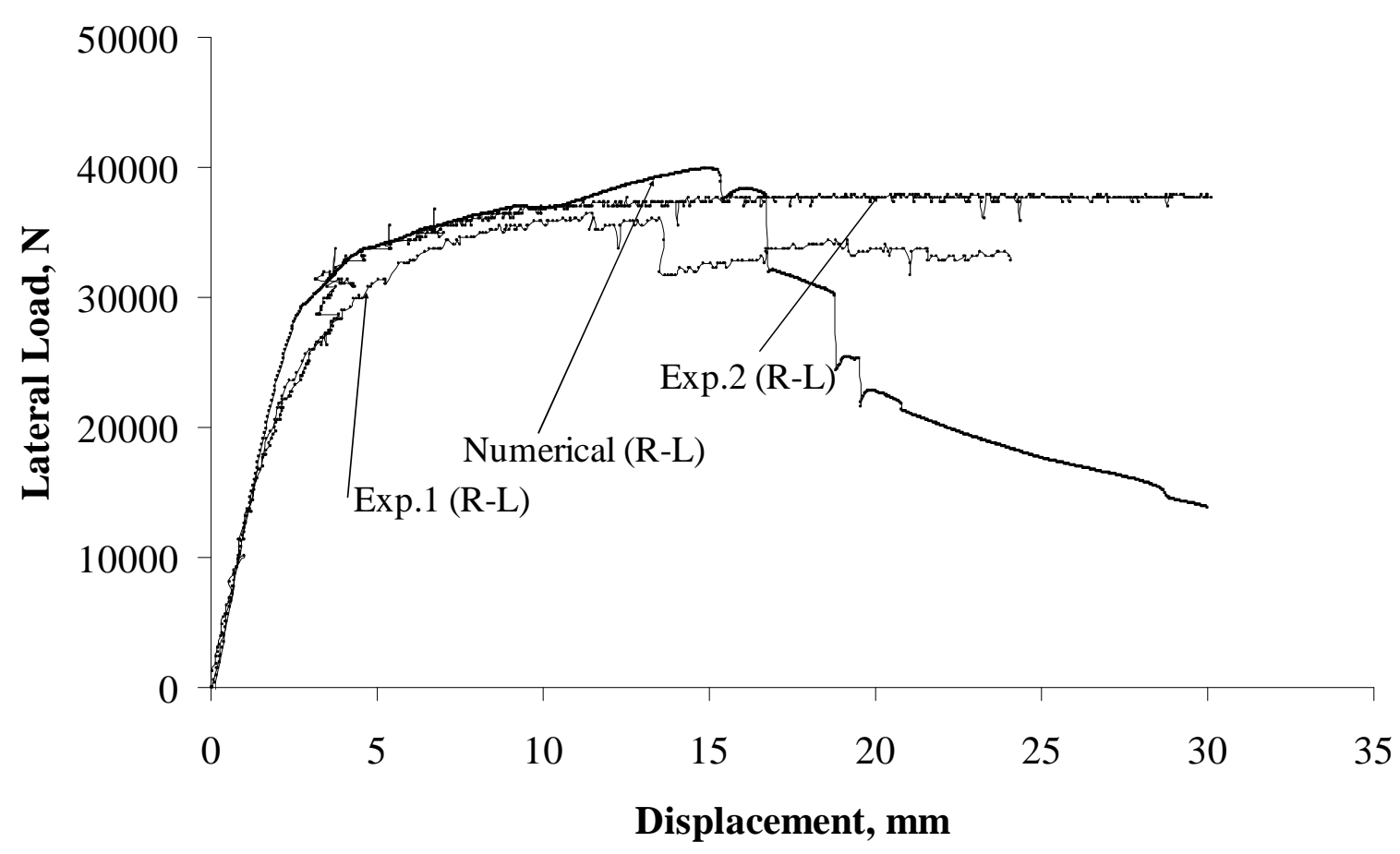

ii) Loading at top right corner (Right to Left (R-L))

a) Axial pre-compression load $=100 \mathrm{kN}$ 


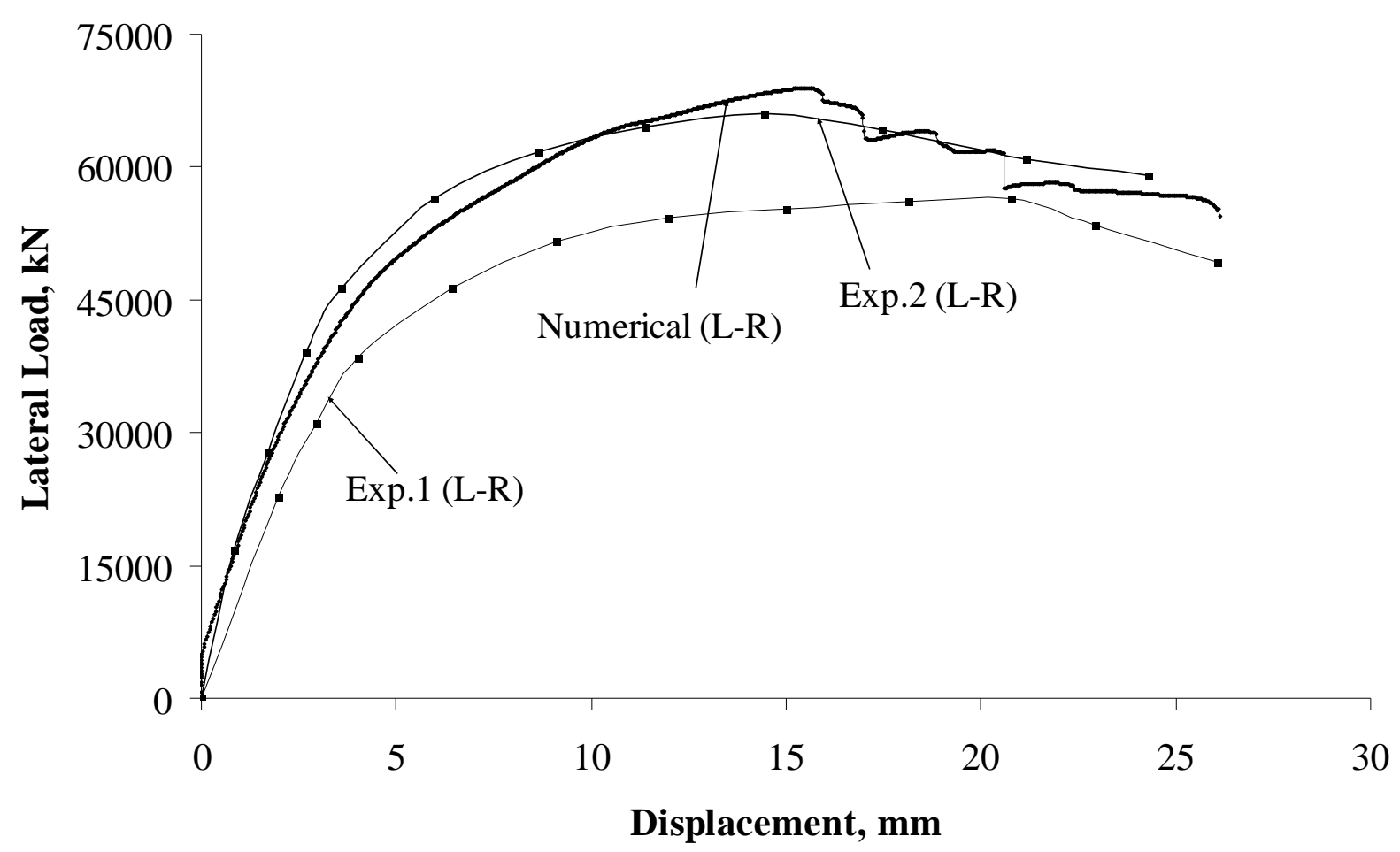

i) Loading at top left corner (Left to Right (L-R))

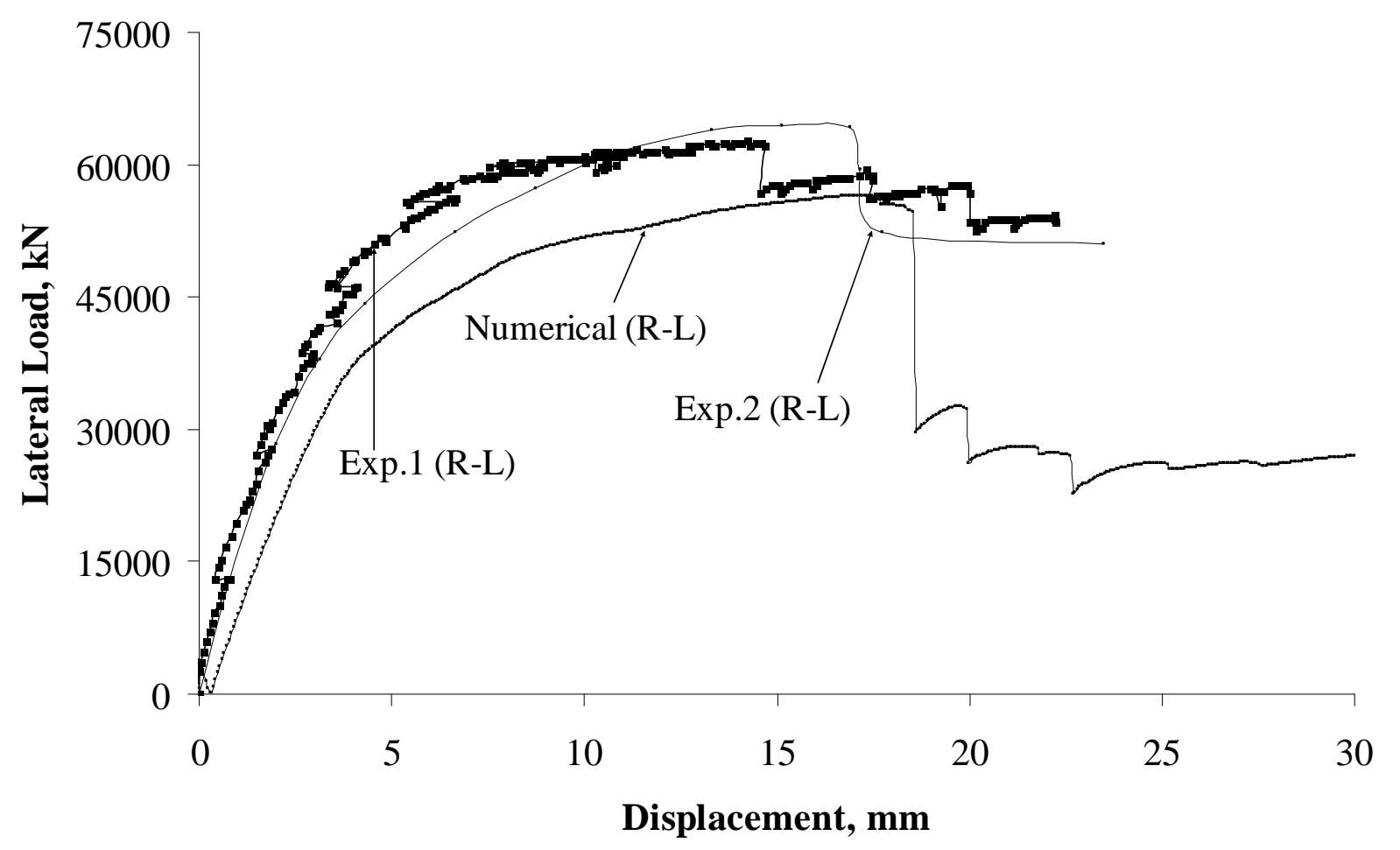

ii) Loading at top right corner (Right to Left (R-L))

b) Axial pre-compression load $=175 \mathrm{kN}$ 


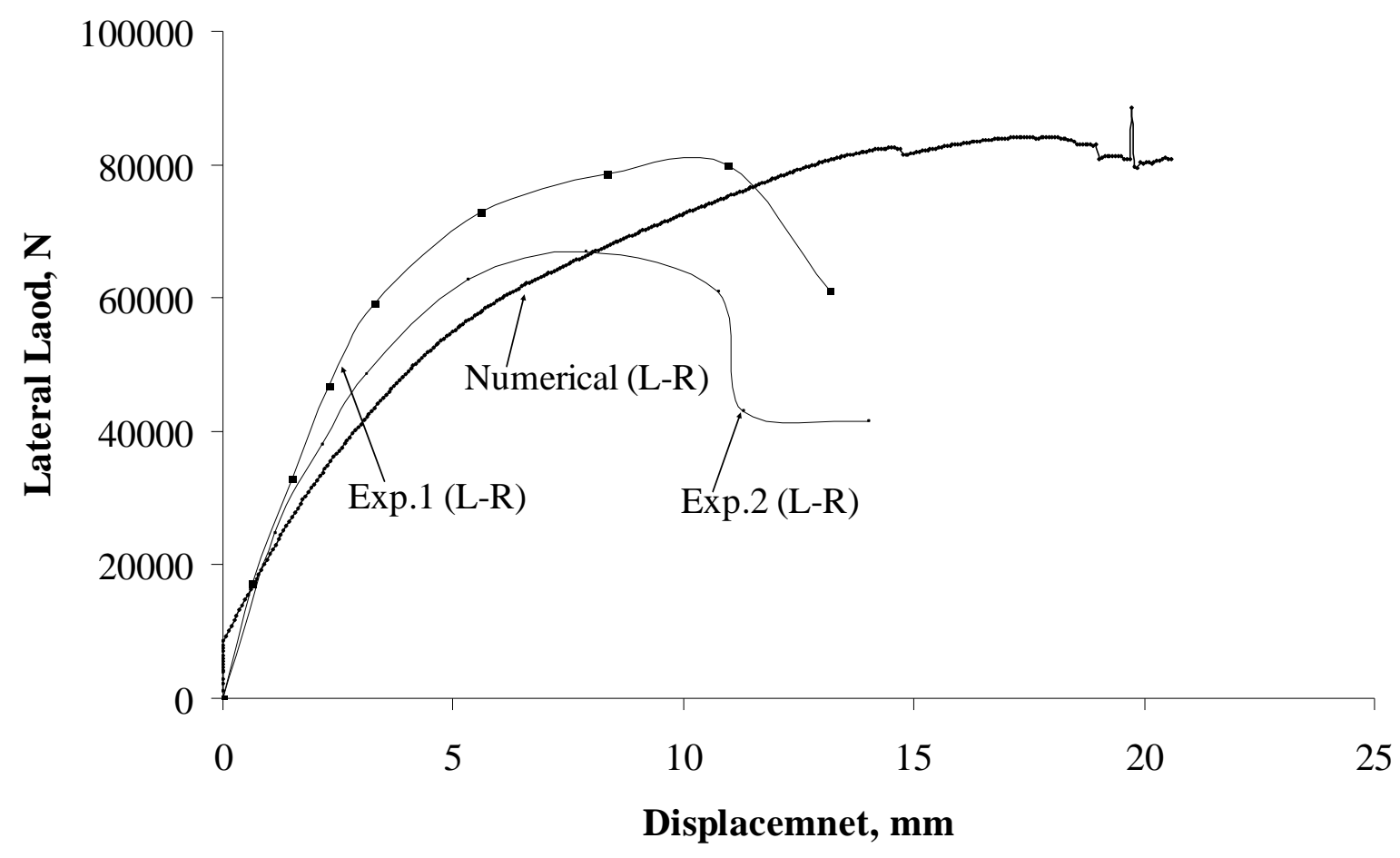

i) Loading at top left corner (Left to Right (L-R))

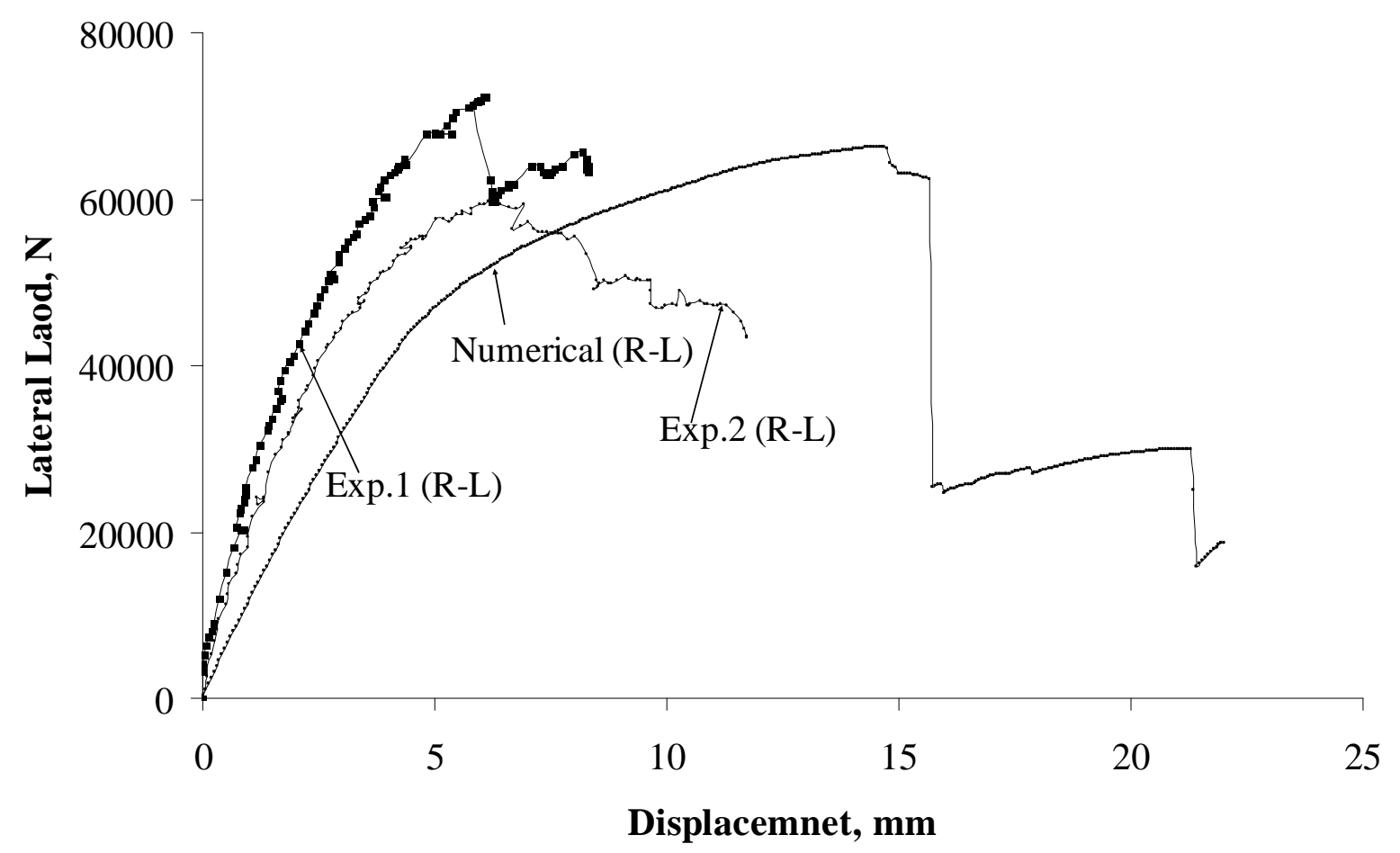

ii) Loading at top right corner (Right to Left (R-L))

c) Axial pre-compression load $=250 \mathrm{kN}$

Figure 14: Load-displacement envelope curves of Type III, Rubble stone masonry 